\title{
SÍNTESE E AVALIAÇÃO DAS ATIVIDADES FOTOPROTETORA, CITOTÓXICA E ANTIVIRAL CONTRA O ZIKA VÍRUS DE DERIVADOS TRIAZÓLICOS DA BENZOFENONA
}

\author{
Ângela M. A. Limaa, Róbson R. Teixeira ${ }^{\mathrm{a}, *, \odot, ~ B i a n c a ~ F . ~ d a ~ S i l v a ~}{ }^{\mathrm{a}}$, Raoni P. Siqueira ${ }^{\mathrm{b}}$, Ítalo E. P. da Silva ${ }^{\mathrm{c}}$, Edjon G. Santos ${ }^{\mathrm{c}}$, \\ Maria Cecília Fernandes ${ }^{\mathrm{a}}$, Victor Hugo Sousa Gonçalves ${ }^{\mathrm{b}}$, Gustavo C. Bressan ${ }^{\mathrm{b}}$, Tiago Antonio de Oliveira Mendes ${ }^{\mathrm{b}}$, Sérgio \\ O. de Paulac ${ }^{c}$, Adílson Vidal Costa ${ }^{\mathrm{d}}$ e Marcelo H. dos Santos ${ }^{\mathrm{a}}$ \\ aDepartamento de Química, Universidade Federal de Viçosa, 36570-900 Viçosa - MG, Brasil \\ bepartamento de Bioquímica e Biologia Molecular, Universidade Federal de Viçosa, 36570-900 Viçosa - MG, Brasil \\ 'Departamento de Biologia Geral, Universidade Federal de Viçosa, 36570-900 Viçosa - MG, Brasil \\ dDepartamento de Química e Física, Centro de Ciências Exatas, Naturais e da Saúde, Universidade Federal do Espírito Santo, \\ 29500-000 Alegre - ES, Brasil
}

Recebido em 01/10/2018; aceito em 24/04/2019; publicado na web em 14/05/2019

\begin{abstract}
SYNTHESIS AND EVALUATION OF THE PHOTOPROTECTIVE, CYTOTOXIC AND ANTIVIRAL ACTIVITY OF BENZOPHENONE DERIVATIVES CONTAINING 1,2,3-TRIAZOLIC PORTIONS. The benzophenones are synthetic and natural compounds presenting a variety of activities, including photoprotective, cytotoxic and antiviral. It is herein described the preparation of a series of twenty-seven benzophenone derivatives bearing 1,2,3-triazole functionalities and the evaluation of their photoprotective, cytotoxic and antiviral on Zika Virus (ZIKV) activities. The compounds were prepared in three steps, namely reduction of benzophenone, alkylation of diphenylmethanol and CuAAC reactions. The in vitro evaluation of the photoprotective activity revealed that the most active derivative 4-((benzhydryloxy)methyl)-1-(4-nitrobenzyl)-1H-1,2,3-triazole (4k) displayed UVB sun protection factor equal to $6,9 \pm 0,53$, which make this compound a possible candidate to be used in formulations for photoprotective applications. In terms of cytotoxicity, the compounds were evaluated against MDA-MB-231 and B16F10 cell lines. It was observed that the compounds were more active against MDA-MB-231 cells and three of them were capable of reducing cell viability by approximately $55 \%$ at $100 \mu \mathrm{mol} \mathrm{L}^{-1}$. In the antiviral screening against ZIKV, compound 4-(3-benzhydryloxy)propyl)-1-(3-methylbenzyl)-1H-1,2,3triazole (5j) was the most effective in mantaining Vero cell viability.
\end{abstract}

Keywords: benzophenone; photoprotective activity; cytotoxicity; antiviral; 1,2,3-triazole.

\section{INTRODUÇÃO}

As benzofenonas são uma classe de substâncias de origem natural e sintética que apresentam considerável variabilidade estrutural, além de possuírem diversas aplicações e atividades biológicas. ${ }^{1-3}$ Dentre as diversas atividades associadas às benzofenonas, uma bem documentada é a ação fotoprotetora.

A exposição aos raios solares por tempo prolongado e sem proteção adequada resulta em diversos efeitos nocivos à saúde, como sensibilidade a luz, manchas, envelhecimento cutâneo, eritema (vermelhidão na pele), despigmentação cutânea e câncer de pele, sendo este último considerado mundialmente uma das causas mais relevantes de mortalidade. ${ }^{4,5}$

O Brasil é considerado um dos países de maior incidência de casos envolvendo câncer de pele. Segundo estimativas apontadas pelo Instituto Nacional do Câncer (INCA), o câncer de pele representa 26\% dos tumores malignos identificados e leva a óbito aproximadamente $10 \%$ dos pacientes. ${ }^{6-9}$ Neste sentido, para prevenir ou diminuir os riscos de câncer cutâneo e demais doenças associadas à exposição excessiva aos raios ultra-violeta (UV), a utilização de protetores solares é de fundamental importância. ${ }^{10}$

Os filtros orgânicos presentes nos protetores solares são constituídos por substâncias químicas, cujas estruturas são compostas essencialmente por anéis aromáticos conectados a um grupo carbonila. Geralmente, essa classe de compostos apresenta um grupo doador ou retirador de elétrons na posição orto ou para do anel aromático. ${ }^{11,12}$ Essas substâncias fotoprotetoras têm por objetivo diminuir os efeitos

*e-mail: robsonr.teixeira@ufv.br deletérios causados pelos raios UV por meio da absorção dos raios incidentes, ou seja, radiação com energias maiores, e transformando-as posteriormente em radiações com energias menores e não prejudiciais aos seres humanos. ${ }^{13,14}$

A eficiência desses filtros é medida em função da sua capacidade em absorver a energia radiante. A combinação de diferentes filtros UVA e UVB, de amplo espectro de absorção em formulações, é uma alternativa para melhorar a eficiência destes e garantir uma maior proteção à pele. ${ }^{15}$ Com a disseminação do conhecimento acerca dos danos provocados pela radiação ultravioleta, a produção e utilização de filtros solares aumentaram exponencialmente ao longo dos anos, representando uma medida eficaz de prevenção ou diminuição dos efeitos prejudiciais causados pelos raios UV. Em virtude disso, diversos filtros orgânicos foram desenvolvidos e comercializados nos últimos tempos. ${ }^{8,16}$ Entretanto, há relatos de problemas relacionados ao uso dos protetores solares. Por exemplo, a benzofenona-3, embora forneça boa ação fotoprotetora contra os raios UVA e UVB, tem seu uso restrito no mercado devido aos efeitos colaterais (irritação na pele e olhos) induzidos após o uso da mesma. ${ }^{17}$ Assim, a busca por novos compostos orgânicos com propriedades fotoprotetoras e que não apresentem problemas relacionados à sua utilização é de potencial interesse.

Duas outras importantes atividades apresentadas pela classe das benzofenonas são antiviral e citotóxica. A grande maioria dos estudos a respeito da atividade antiviral de benzofenonas envolveu sua ação anti-HIV. ${ }^{3}$ Com respeito à citotoxicidade, os compostos pertencentes a essa classe têm sido avaliados contra uma grande variedade de linhagens celulares e com resultados variados com respeito à eficácia destes. ${ }^{3}$ 
Dentro desse contexto, considerando-se a atividade fotoprotetora descrita para derivados da benzofenona e visando obter novas substâncias que possam ser utilizadas como possíveis filtros orgânicos em protetores solares, que sejam mais eficientes ao proteger a pele exposta contra os raios UV e que apresentem mínimos efeitos adversos, descreve-se neste artigo a síntese e a avaliação in vitro da atividade fotoprotetora de derivados da benzofenona contendo o núcleo 1,2,3-triazólico. Em vista do interesse do nosso grupo de pesquisa com respeito ao efeito contra linhagens de células cancerígenas e atividade antiviral de compostos orgânicos, ${ }^{18-21}$ e levando-se em conta relatos de atividades citotóxica e antiviral tanto de compostos triazólicos ${ }^{22}$ quanto de benzofenonas, descreve-se ainda neste trabalho os resultados da avaliação das atividades dos derivados triazólicos da benzofenona contra duas linhagens de células cancerígenas (MDAMB-231 e B16F10) bem como contra o Zika Vírus.

\section{PARTE EXPERIMENTAL}

\section{Síntese}

\section{Generalidades}

Foram utilizados reagentes de grau P.A. para a síntese dos compostos.

Benzofenona, boroidreto de sódio $\left(\mathrm{NaBH}_{4}\right)$, brometo de tetrabutilamônio $\left((\mathrm{Bu})_{4} \mathrm{NBr}\right)$, brometo de propargila (3-bromoprop-1-ino), pent-4-in-1-ol, brometo de benzila, brometo de 3-metilbenzila, brometo de 4-metilbenzila, brometo de 2-bromobenzila, álcool 4-fluorobenzílico, álcool 4-clorobenzílico, álcool 4-bromobenzílico, álcool 4-iodobenzílico, álcool 4-nitrobenzílico, álcool 4-metoxibenzílico, álcool 4-trifluorometoxibenzílico, álcool 4-trifluorobenzílico, álcool 4-isopropilbenzílico, sulfato de cobre pentaidratado e ascorbato de sódio, foram adquiridas comercialmente da Sigma Aldrich (St. Louis, MO, Estados Unidos) e utilizados sem prévia purificação. Diclorometano, álcool etílico, acetato de etila, hexano, éter etílico, cloreto de sódio, hidróxido de sódio, carbonato de sódio, tolueno e ácido clorídrico foram adquiridos da Vetec (Rio de Janeiro, Brasil).

As análises por cromatografia em camada delgada (CCD) foram realizadas utilizando-se placas cromatográficas de sílica-gel impregnadas sobre alumínio. Após eluição, as placas de CCD foram observadas sob luz ultravioleta $(\lambda=254 \mathrm{~nm})$ e reveladas com solução de permanganato de potássio ( $3 \mathrm{~g}$ de $\mathrm{KMnO}_{4}, 20 \mathrm{~g}$ de $\mathrm{K}_{2} \mathrm{CO}_{3}$, $5 \mathrm{~mL}$ de $\mathrm{NaOH} 5 \% \mathrm{~m} / \mathrm{v}, 300 \mathrm{~mL}$ de água). As separações em coluna cromatográfica foram realizadas usando sílica-gel (70-230 mesh) como fase estacionária. Os solventes utilizados como eluentes foram usados sem prévia purificação. Os espectros no infravermelho (IV) foram obtidos empregando-se a técnica da reflectância total atenuada (ATR) em equipamento Varian 660 com acessório GladiATr. Os espectros de ressonância magnética nuclear de hidrogênio (RMN de ${ }^{1} \mathrm{H}, 300 \mathrm{MHz}$ ) e de carbono (RMN de ${ }^{13} \mathrm{C}, 75 \mathrm{MHz}$ ) foram obtidos em um espectrômetro VARIAN MERCURY 300. Foram utilizados como solvente o clorofórmio $\left(\mathrm{CDCl}_{3}\right)$ deuterado. As temperaturas de fusão foram determinadas em aparelho MQAPF-302 e não foram corrigidas. As leituras das absorbâncias na faixa de comprimento de onda 290-320 nm foram realizadas em um espectrofotômetro (leitor de Elisa) Multiskan Go.

\section{Preparação do difenilmetanol (1)}

A um balão de fundo redondo de $100 \mathrm{~mL}$, contendo uma barra de agitação magnética, foram adicionados a benzofenona $(3,00 \mathrm{~g}$; $16,4 \mathrm{mmol}$ ) e $30,0 \mathrm{~mL}$ de etanol. A mistura resultante foi mantida sob agitação por 30 minutos. Em seguida, foram adicionados a essa mistura 15,0 mL de solução de $\mathrm{NaBH}_{4}(0,685 \mathrm{~g} ; 18,1 \mathrm{mmol})$ em etanol gota a gota. Após a adição, a mistura foi mantida sob agitação por mais 40 minutos a temperatura ambiente. Decorrido este período, a análise da mistura por CCD mostrou que a benzofenona havia sido completamente consumida. A mistura reagente foi, então, transferida para um béquer, mantido em banho de gelo, contendo $40,0 \mathrm{~mL}$ de água e $9,00 \mathrm{~mL}$ de $\mathrm{HCl}$ concentrado, resultando na formação de um precipitado branco. O precipitado foi filtrado a vácuo e lavado com água gelada (3 x 20,0 mL). O sólido branco obtido, difenilmetanol (1), não foi submetido a nenhum processo subsequente de purificação. $\mathrm{O}$ composto 1 foi obtido em $92 \%$ de rendimento (2,78 g; $15,1 \mathrm{mmol})$. CCD: $R_{\mathrm{f}}=0,36$ (hexano-acetato de etila $8: 1 \mathrm{v} / \mathrm{v}$ ). $\mathrm{T}_{\mathrm{f}}=62,8-63,4^{\circ} \mathrm{C}$. IV (ATR) $-v_{\text {max }} / \mathrm{cm}^{-1}: 3323,3084,3059,3025,2886,3025,1959$, 1894, 1805, 1666, 1596, 1453, 1445, 1393, 1346, 1266, 1180, 1171, 1032, 1017, 751, 733, 694, 651, 600, 540. RMN de ${ }^{1} \mathrm{H}(300 \mathrm{MHz}$, $\left.\mathrm{CDCl}_{3}\right) \delta: 5,84(\mathrm{~s}, 1 \mathrm{H}) ; 7,26-7,41(\mathrm{~m}, 10 \mathrm{H}) . \mathrm{RMN} \mathrm{de}{ }^{13} \mathrm{C}(75 \mathrm{MHz}$, $\left.\mathrm{CDCl}_{3}\right) \delta: 76,2 ; 126,5 ; 127,5 ; 128,5 ; 143,8$.

\section{Preparação do prop-2-in-1-ilóxi difenilmetano (2)}

A um balão de fundo redondo de $50 \mathrm{~mL}$, contendo uma barra de agitação magnética, foram adicionados o difenilmetanol (1) (1,00 g; $5,43 \mathrm{mmol})$, o brometo de tetrabutilamônio $(0,175 \mathrm{~g} ; 0,542 \mathrm{mmol})$, $10,0 \mathrm{~mL}$ de solução aquosa de $\mathrm{NaOH} 35 \% \mathrm{~m} / \mathrm{v}$ e $12,0 \mathrm{~mL}$ de tolueno. A mistura resultante foi resfriada em banho de gelo e mantida sob agitação magnética por 1 hora. Em seguida, foram adicionados a essa mistura 1,50 mL (16,3 mmol) de brometo de propargila. Após a adição, a mistura de reação foi mantida sob agitação por mais 2 horas à temperatura ambiente. Decorrido esse período, o volume da reação foi reduzido em evaporador rotativo. Posteriormente, adicionou-se solução saturada de cloreto de sódio à mistura que, então, foi transferida para um funil de separação e a fase aquosa foi extraída com éter etílico ( 3 x 20,0 mL). Os extratos orgânicos foram reunidos e a fase orgânica resultante foi seca com sulfato de sódio anidro, filtrada e concentrada sob pressão reduzida. O material resultante foi purificado por cromatografia em coluna de sílica-gel utilizando-se como eluente hexano-acetato de etila $(8: 1 \mathrm{v} / \mathrm{v})$. O composto 2 foi obtido como um óleo incolor em $78 \%$ de rendimento $(0,941 \mathrm{~g} ; 4,23 \mathrm{mmol})$. CCD: $R_{\mathrm{f}}=0,70$ (hexano-acetato de etila 8:1 v/v). IV (ATR) $\overline{\mathrm{v}}_{\max } / \mathrm{cm}^{-1}$ : 3279, 3062, 3024, 2954, 2915, 2875, 2113, 2038, 1978, 1886, 1822, 1760, 1662, 1596, 1491, 1452, 1363, 1348, 1265, 1184, 1092, 1065 , 1021, 959, 911, 745, 696, 635, 578, 525. RMN de ${ }^{1} \mathrm{H}(300 \mathrm{MHz}$, $\left.\mathrm{CDCl}_{3}\right) \delta: 2,49(\mathrm{~s}, 1 \mathrm{H}) ; 4,18(\mathrm{~s}, 1 \mathrm{H}) ; 5,71(\mathrm{~s}, 2 \mathrm{H}) ; 7,41-7,29(\mathrm{~m}$, $10 \mathrm{H})$. $\mathrm{RMN} \mathrm{de}{ }^{13} \mathrm{C}\left(75 \mathrm{MHz}, \mathrm{CDCl}_{3}\right) \delta: 55,8 ; 74,6 ; 79,7 ; 81,6127,3$; 127,$7 ; 128,4 ; 141,1$.

\section{Preparação do pent-4-in-ilóxi difenilmetano (3)}

$\mathrm{O}$ alquino 3 foi sintetizado a partir do pent-4-in-1-ilmetanosulfonato, ${ }^{19}$ utilizando um procedimento semelhante ao descrito para o composto 2. Porém, a mistura reagente foi mantida sob agitação magnética à temperatura de $50{ }^{\circ} \mathrm{C}$ por um período de 24 horas. $\mathrm{O}$ composto 3 foi obtido como um óleo incolor em $65 \%$ de rendimento $(0,616 \mathrm{~g} ; 2,46 \mathrm{mmol})$. CCD R $\mathrm{f}=0,79$ (hexano-acetato de etila 8:1 v/v). IV (ATR) $\bar{v}_{\max } / \mathrm{cm}^{-1}: 3294,3087,3064,3028,2954,2929,2861,2156$, 2000-1660, 1598, 1493, 1452, 1303, 1073, 920, 831, 739, 696, 620. RMN de ${ }^{1} \mathrm{H}\left(300 \mathrm{MHz}, \mathrm{CDCl}_{3}\right) \delta: 1,89-1,83(\mathrm{~m}, 2 \mathrm{H}) ; 1,94-1,92(\mathrm{~m}$, $1 \mathrm{H}) ; 2,37\left(\mathrm{td}, 2 \mathrm{H}, J_{1}=7,1 \mathrm{~Hz}\right.$ e $\left.J_{2}=2,3 \mathrm{~Hz}\right) ; 5,36(\mathrm{~s}, 1 \mathrm{H}) ; 7,37-7,27$ (m, 10H). RMN de ${ }^{13} \mathrm{C}\left(75 \mathrm{MHz}, \mathrm{CDCl}_{3}\right) \delta: 15,4 ; 28,8 ; 67,4 ; 68,4$; 83,$7 ; 84,0 ; 126,9 ; 127,3 ; 128,3$.

\section{Procedimento geral para a obtenção dos derivados}

\section{1,2,3-triazólicos da benzofenona $\mathbf{4 a - 4 n}$}

A um balão de fundo redondo de $25 \mathrm{~mL}$, contendo uma barra de agitação magnética, foram adicionados a azida (1,10 equivalente), o alquino 2 ( 1,00 equivalente), ascorbato de sódio ( 0,400 equivalente), 2,00 $\mathrm{mL}$ de água destilada e 2,00 $\mathrm{mL}$ de diclorometano. Em seguida, 
foi adicionado o $\mathrm{CuSO}_{4} \cdot 5 \mathrm{H}_{2} \mathrm{O}(0,200$ equivalente). A mistura de reação permaneceu sob agitação por 2 horas à temperatura ambiente. Após o término da reação (determinado via análise por $\mathrm{CCD}$ ) a mistura resultante foi lavada com solução saturada de $\mathrm{Na}_{2} \mathrm{CO}_{3}$ e a fase aquosa extraída com diclorometano $(3 \times 20 \mathrm{~mL})$. Os extratos orgânicos foram reunidos e a fase orgânica foi seca com sulfato de sódio anidro, filtrada e concentrada sob pressão reduzida. O material resultante foi purificado por cromatografia em coluna de sílica-gel utilizando-se como eluente uma mistura de hexano-acetato de etila-diclorometano (3:1:3 v/v). Os derivados 1,2,3-triazólicos da benzofenona $4 \mathbf{a}-\mathbf{4 n}$ foram obtidos com rendimentos variando de $42 \%-88 \%$. As informações pertinentes às reações envolvidas na preparação dos compostos 4a-4n e os dados que suportam as estruturas destes se encontram descritas a seguir.

\section{4-(metilbenzidrilóxi)-1-(benzil)-1H-1,2,3-triazol (4a)}

Sólido branco obtido em $83 \%$ de rendimento $(0,200 \mathrm{~g}$, $0,563 \mathrm{mmol})$ a partir de $0,100 \mathrm{~g}(0,750 \mathrm{mmol})$ de benzilazida, 0,0540 $\mathrm{g}(0,272 \mathrm{mmol})$ de ascorbato de sódio, $0,151 \mathrm{~g}(0,680 \mathrm{mmol})$ do alquino 2 e $0,0340 \mathrm{~g}(0,136 \mathrm{mmol})$ de $\mathrm{CuSO}_{4} \cdot 5 \mathrm{H}_{2} \mathrm{O}$. CCD R $\mathrm{f}=0,61$ (hexano-acetato de etila-diclorometano 3:1:3 v/v). $\mathrm{T}_{\mathrm{f}}: 68,9-70,6{ }^{\circ} \mathrm{C}$. IV (ATR) $\overline{\mathrm{v}}_{\max } / \mathrm{cm}^{-1}: 3139,3083,3058,3031,2960,2925,2894,2865$, 1949, 1887, 1803, 1725, 1602, 1560, 1493, 1453, 1103, 1073, 1053, 1053, 910, 819, 757, 735, 690. RMN de ${ }^{1} \mathrm{H}\left(300 \mathrm{MHz}, \mathrm{CDCl}_{3}\right) \delta$ : 4,66 (s, 2H); 5,49-5,51 (m, 3H); 7,21-7,39 (m, 15H); 7,45 (s, 1H). $\mathrm{RMN}$ de ${ }^{13} \mathrm{C}\left(75 \mathrm{MHz}, \mathrm{CDCl}_{3}\right) \delta: 54,1 ; 62,5 ; 83,0 ; 122,4 ; 127,1$; 127,$5 ; 128,0 ; 128,4 ; 128,7 ; 129,0 ; 134,6 ; 141,6 ; 145,8$.

\section{4-(metilbenzidrilóxi)-1-(4-bromobenzil)-1H-1,2,3-triazol (4b)}

Sólido branco obtido em $78 \%$ de rendimento $(0,179 \mathrm{~g}$; $0,412 \mathrm{mmol})$ a partir de $0,123 \mathrm{~g}(0,579 \mathrm{mmol})$ de 4-bromobenzilazida, $0,0410 \mathrm{~g}(0,210 \mathrm{mmol})$ de ascorbato de sódio, $0,122 \mathrm{~g}(0,526 \mathrm{mmol})$ do alquino $2 \mathrm{e} 0,0260 \mathrm{~g}(0,105 \mathrm{mmol})$ de $\mathrm{CuSO}_{4} \cdot 5 \mathrm{H}_{2} \mathrm{O} \cdot \mathrm{CCD} \mathrm{R} \mathrm{R}_{\mathrm{f}}=0,46$ (hexano-acetato de etila-diclorometano 3:1:3 v/v). $\mathrm{T}_{\mathrm{f}}: 98,7-99,1^{\circ} \mathrm{C}$. IV (ATR) $\bar{v}_{\max } / \mathrm{cm}^{-1}: 3126,3087,3027,2919,2869,1895,1808,1592$, 1562, 1489, 1454, 1217, 1179, 1128, 1090, 1069, 1008, 835, 815, 788, 743, 696, 603, 479. RMN de ${ }^{1} \mathrm{H}\left(300 \mathrm{MHz}, \mathrm{CDCl}_{3}\right) \delta: 4,65$ (s, $2 \mathrm{H}) ; 5,44(\mathrm{~s}, 2 \mathrm{H}), 5,50(\mathrm{~s}, 1 \mathrm{H}) ; 7,13(\mathrm{~d}, 2 \mathrm{H}, \mathrm{J}=8,4 \mathrm{~Hz}) ; 7,24-7,36(\mathrm{~m}$, $10 \mathrm{H}) ; 7,45(\mathrm{~s}, 1 \mathrm{H}) ; 7,49(\mathrm{~d}, 2 \mathrm{H}, \mathrm{J}=8,4 \mathrm{~Hz})$. RMN de ${ }^{13} \mathrm{C}(75 \mathrm{MHz}$, $\left.\mathrm{CDCl}_{3}\right)$ $\delta: 53,4 ; 62,5 ; 83,1 ; 122,4 ; 122,8 ; 127,0 ; 127,6 ; 128,4 ; 129,7$; 132,$2 ; 133,6 ; 141,6 ; 146,0$.

\section{4-(metilbenzidrilóxi)-1-(4-fluorobenzil)-1H-1,2,3-triazol (4c)}

Sólido branco obtido em $82 \%$ de rendimento $(0,138 \mathrm{~g}$; $0,370 \mathrm{mmol})$ a partir de $0,075 \mathrm{~g}(0,495 \mathrm{mmol})$ de 4-fluorobenzilazida, $0,035 \mathrm{~g}(0,180 \mathrm{mmol})$ de ascorbato de sódio, 0,100 g $(0,450 \mathrm{mmol})$ do alquino 2 e $0,022 \mathrm{~g}(0,090 \mathrm{mmol})$ de $\mathrm{CuSO}_{4} \cdot 5 \mathrm{H}_{2} \mathrm{O}$. CCD R $\mathrm{f}_{\mathrm{f}}=0,64$ (hexano-acetato de etila-diclorometano $3: 1: 3 \mathrm{v} / \mathrm{v}$ ). $\mathrm{T}_{\mathrm{f}}: 74,7-75,4^{\circ} \mathrm{C}$. IV (ATR) $\bar{v}_{\text {max }} / \mathrm{cm}^{-1}: 3129,3087,3027,2867,1974,1895,1808,1603$, 1510, 1493, 1453, 1229, 1156, 1125, 1105, 1051, 927, 842, 743, 787, 696, 531. RMN de ${ }^{1} \mathrm{H}\left(300 \mathrm{MHz}, \mathrm{CDCl}_{3}\right) \delta:$ 4,65 (s, 2H); 5,46 (s, $2 \mathrm{H}) ; 5,50(\mathrm{~s}, 1 \mathrm{H}) ; 7,05$ (t, 2H, $J=8,4 \mathrm{~Hz}) ; 7,23-7,36(\mathrm{~m}, 12 \mathrm{H}) ; 7,45$ (s, $1 \mathrm{H}) . \mathrm{RMN} \mathrm{de}{ }^{13} \mathrm{C}\left(75 \mathrm{MHz}, \mathrm{CDCl}_{3}\right) \delta: 53,3 ; 62,5 ; 83,1 ; 116,0(\mathrm{~d}$, $\left.J_{C-F}=21,8 \mathrm{~Hz}\right) ; 122,3 ; 127,1 ; 127,6 ; 128,4 ; 130,0\left(\mathrm{~d}, J_{C-F}=8,3 \mathrm{~Hz}\right)$; $130,5\left(\mathrm{~d}, J_{C-F}=3,0 \mathrm{~Hz}\right) ; 162,8\left(\mathrm{~d}, J_{C-F}=246,6 \mathrm{~Hz}\right)$.

\section{4-(metilbenzidrilóxi)-1-(4-clorobenzil)-1H-1,2,3-triazol (4d)}

Sólido branco obtido em $79 \%$ de rendimento $(0,139 \mathrm{~g}$; $0,356 \mathrm{mmol})$ a partir de $0,0830 \mathrm{~g}(0,495 \mathrm{mmol})$ de 4-clorobenzilazida, 0,0350 g (0,180 mmol) de ascorbato de sódio, 0,100 g (0,450 mmol) do alquino 2 e $0,0220 \mathrm{~g}(0,0900 \mathrm{mmol})$ de $\mathrm{CuSO}_{4} \cdot 5 \mathrm{H}_{2} \mathrm{O}$. CCD $\mathrm{R}_{\mathrm{f}}=0,63$ (hexano-acetato de etila-diclorometano $3: 1: 3 \mathrm{v} / \mathrm{v}$ ). $\mathrm{T}_{\mathrm{f}}$ : 94,4-95,2 ${ }^{\circ} \mathrm{C}$. IV (ATR) $\overline{\mathrm{v}}_{\max } / \mathrm{cm}^{-1}: 3129,3089,3062,3031,2915$,
2870, 1596, 1560, 1491, 1454, 1410, 1334, 1322, 1217, 1181, 1128, 1089, 1053, 1024, 1013, 928, 837, 819, 790, 744, 697. RMN de ${ }^{1} \mathrm{H}$ $\left(300 \mathrm{MHz} \mathrm{CDCl}_{3}\right) \delta:$ 4,65 (s, 2H); 5,46 (s, 2H); 5,50 (s, 1H); 7,19 (d, $2 \mathrm{H}, J=8,1 \mathrm{~Hz}) ; 7,29(\mathrm{~m}, 12 \mathrm{H}) ; 7,45(\mathrm{~s}, 1 \mathrm{H})$. RMN de ${ }^{13} \mathrm{C}(75 \mathrm{MHz}$, $\mathrm{CDCl}_{3}$ ) $\delta: 53,3,62,5 ; 83,1 ; 122,4,127,1 ; 127,6 ; 128,4 ; 129,2 ; 129,4$; 133,$1 ; 134,7 ; 141,6 ; 146,0$.

\section{4-(metilbenzidrilóxi)-1-(4-trifluorometilbenzil)-1H-1,2,3-triazol (4e)}

Sólido branco obtido em $68 \%$ de rendimento $(0,150 \mathrm{~g}$; $0,354 \mathrm{mmol})$ a partir de $0,115 \mathrm{~g}(0,574 \mathrm{mmol})$ de 4-trifluorobenzilazida, 0,0410 g (0,209 mmol) de ascorbato de sódio, 0,116 g (0,522 mmol) do alquino $2 \mathrm{e} 0,0260 \mathrm{~g}(0,104 \mathrm{mmol}) \mathrm{de} \mathrm{CuSO}_{4} \cdot 5 \mathrm{H}_{2} \mathrm{O} . \mathrm{CCD} \mathrm{R}_{\mathrm{f}}=0,46$ (hexano-acetato de etila-diclorometano 3:1:3 v/v). $\mathrm{T}_{\mathrm{f}}: 117,0-117,8^{\circ} \mathrm{C}$. IV (ATR) $\overline{\mathrm{v}}_{\text {max }} / \mathrm{cm}^{-1}: 3131,3091,3031,2915,2871,1974,1901,1822$, 1620, 1560, 1493, 1454, 1421, 1321, 1161, 1123, 1008, 1073, 912, 829, 793, 751, 697, 603. RMN de ${ }^{1} \mathrm{H}\left(300 \mathrm{MHz}, \mathrm{CDCl}_{3}\right) \delta: 4,67$ (s, 2H); 5,51 (s, 1H); 5,56 (s, 2H); 7,24-7,37 (m, 12H); 7,49 (s, 1H); 7,63 (d, $2 \mathrm{H}, J=8,4 \mathrm{~Hz})$. RMN de ${ }^{13} \mathrm{C}\left(75 \mathrm{MHz}, \mathrm{CDCl}_{3}\right) \delta: 53,4 ; 62,5 ; 83,2$; 122,$5 ; 123,7\left(\mathrm{q}, J_{C-F}=269,3 \mathrm{~Hz}\right) ; 126,0\left(\mathrm{q}, J_{C-F}=3,8 \mathrm{~Hz}\right) ; 127,0 ; 127,6$; 128,$2 ; 128,4 ; 130,9$ (q, $\left.J_{C-F}=33,0 \mathrm{~Hz}\right) ; 138,5 ; 141,6 ; 146,2$.

\section{4-(metilbenzidrilóxi)-1-(2-bromobenzil)-1H-1,2,3-triazol (4f)}

Sólido branco obtido em $65 \%$ de rendimento $(0,162 \mathrm{~g}$; $0,373 \mathrm{mmol})$ a partir de $0,133 \mathrm{~g}(0,628 \mathrm{mmol})$ de 2-bromobenzilazida, $0,0450 \mathrm{~g}(0,228 \mathrm{mmol})$ de ascorbato de sódio, $0,127 \mathrm{~g}(0,571 \mathrm{mmol})$ do alquino 2 e $0,028 \mathrm{~g}(0,114 \mathrm{mmol})$ de $\mathrm{CuSO}_{4} \cdot 5 \mathrm{H}_{2} \mathrm{O} . \mathrm{CCD} \mathrm{R}_{\mathrm{f}}=0,61$ (hexano-acetato de etila-diclorometano $3: 1: 3 \mathrm{v} / \mathrm{v}$ ). $\mathrm{T}_{\mathrm{f}}: 88,1-89,0{ }^{\circ} \mathrm{C}$. IV (ATR) $\overline{\mathrm{v}}_{\text {max }} / \mathrm{cm}^{-1}: 3137,3052,3027,2919,2865,1974,1812,1710$, 1652, 1598, 1492, 1452, 1436, 1319, 1268, 1060, 1021, 947, 826, 743, 648, 606, 697, 544. RMN de ${ }^{1} \mathrm{H}\left(300 \mathrm{MHz}, \mathrm{CDCl}_{3}\right) \delta:$ 4,67 (s, 2H); $5,51(\mathrm{~s}, 1 \mathrm{H}) ; 5,64(\mathrm{~s}, 2 \mathrm{H}) ; 7,14\left(\mathrm{dd}, 1 \mathrm{H}, J_{1}=7,3 \mathrm{~Hz}\right.$ e $\left.J_{2}=1,3 \mathrm{~Hz}\right)$; 7,22-7,36 (m, 12H); 7,56 (s, 1H); 7,62 (d, 1H, J = 8,1 Hz).

\section{4-(metilbenzidrilóxi)-1-(4-iodobenzil)-1H-1,2,3-triazol (4g)}

Sólido branco obtido em $66 \%$ de rendimento $(0,228 \mathrm{~g}$; 0,473 $\mathrm{mmol})$ a partir de $0,205 \mathrm{~g}(0,792 \mathrm{mmol})$ de 4-iodobenzilazida, 0,0570 g $(0,288 \mathrm{mmol})$ de ascorbato de sódio, 0,160 g $(0,720 \mathrm{mmol})$ do alquino $2 \mathrm{e} 0,0360 \mathrm{~g}(0,144 \mathrm{mmol})$ de $\mathrm{CuSO}_{4} \cdot 5 \mathrm{H}_{2} \mathrm{O}$. CCD $\mathrm{R}_{\mathrm{f}}=0,67$ (hexano-acetato de etila-diclorometano 3:1:3 v/v). $\mathrm{T}_{\mathrm{f}}: 111,2-112,8^{\circ} \mathrm{C}$. IV (ATR) $\overline{\mathrm{v}}_{\max } / \mathrm{cm}^{-1}: 3129,3089,3058,3027$, 2921, 2868, 1968, 1901, 1812, 1589, 1560, 1485, 1454, 1428, 1403, 1334, 1320, 1217, 1128, 1092, 1053, 1004, 928, 835, 610, 786, 742, 696, 602, 473. RMN de ${ }^{1} \mathrm{H}\left(300 \mathrm{MHz}, \mathrm{CDCl}_{3}\right) \delta:$ 4,65 (s, 2H); 5,43 (s, 2H); 5,49 (s, 1H); 7,00 (d, 2H, $J=7,8 \mathrm{~Hz}) ; 7,24-7,35(\mathrm{~m}, 10 \mathrm{H})$; 7,44 (s, 1H); 7,70 (d, 2H, J=7,8 Hz). RMN de ${ }^{13} \mathrm{C}\left(75 \mathrm{MHz}, \mathrm{CDCl}_{3}\right)$ $\delta$ : 53,$5 ; 62,5 ; 83,1 ; 94,5 ; 122,4 ; 127,0 ; 127,6 ; 128,4 ; 129,8 ; 134,2$; 138,$2 ; 141,6 ; 146,0$.

\section{4-(metilbenzidrilóxi)-1-(4-isopropilbenzil)-1H-1,2,3-triazol (4h)}

Sólido branco obtido em $79 \%$ de rendimento $(0,212 \mathrm{~g}$; $0,533 \mathrm{mmol})$ a partir de $0,130 \mathrm{~g}(0,742 \mathrm{mmol})$ de 4-isopropilbenzilazida, 0,0530 g $(0,270 \mathrm{mmol})$ de ascorbato de sódio, 0,150 g $(0,675 \mathrm{mmol})$ do alquino $2 \mathrm{e} 0,0340 \mathrm{~g}(0,136 \mathrm{mmol})$ de $\mathrm{CuSO}_{4} \cdot 5 \mathrm{H}_{2} \mathrm{O}$. CCD $\mathrm{R}_{\mathrm{f}}=0,73$ (hexano-acetato de etila-diclorometano 3:1:3 v/v). $\mathrm{T}_{\mathrm{f}}: 88,1-89,4^{\circ} \mathrm{C}$. IV (ATR) $\overline{\mathrm{V}}_{\max } / \mathrm{cm}^{-1}: 3087,3056,3031,2955,2921$, 2885, 2865, 1974, 1897, 1814, 1697, 1597, 1560, 1512, 1493, 1453, $1391,1055,1006,911,840,789,740,722,702,648,605$. RMN de ${ }^{1} \mathrm{H}\left(300 \mathrm{MHz}, \mathrm{CDCl}_{3}\right) \delta: 1,25$ (d, 6H, $\left.J_{1}=6,9 \mathrm{~Hz}\right) ; 2,91$ (sept, $1 \mathrm{H}$, $J=6,9 \mathrm{~Hz}) ; 4,65$ (s, 2H); 5,47 (s, 2H); 5,50 (s, 1H); 7,19-7,35 (m, $14 \mathrm{H}) ; 7,44$ (s, 1H). RMN de ${ }^{13} \mathrm{C}\left(75 \mathrm{MHz}, \mathrm{CDCl}_{3}\right) \delta: 23,9 ; 33,8$; 53,$9 ; 62,5 ; 83,0 ; 122,4 ; 127,1 ; 127,1 ; 127,5 ; 128,2 ; 128,4 ; 131,9$; 141,$6 ; 145,7 ; 149,5$. 
4-(metilbenzidrilóxi)-1-(4-metoxibenzil)-1H-1,2,3-triazol (4i)

Sólido branco obtido em $74 \%$ de rendimento $(0,193 \mathrm{~g}$; $0,500 \mathrm{mmol})$ a partir de $0,121 \mathrm{~g}(0,741 \mathrm{mmol})$ de 4-metoxibenzilazida, $0,0530 \mathrm{~g}(0,270 \mathrm{mmol})$ de ascorbato de sódio, $0,150 \mathrm{~g}(0,675 \mathrm{mmol})$ do alquino 2 e $0,0340 \mathrm{~g}(0,136 \mathrm{mmol}) \mathrm{de} \mathrm{CuSO}_{4} \cdot 5 \mathrm{H}_{2} \mathrm{O} \cdot \mathrm{CCD} \mathrm{R}_{\mathrm{f}}=0,69$ (hexano-acetato de etila-diclorometano 3:1:3 v/v). $\mathrm{T}_{\mathrm{f}}: 84,7-85,5^{\circ} \mathrm{C}$. IV (ATR) $\bar{v}_{\max } / \mathrm{cm}^{-1}: 3126,3079,3027,2954,2931,2900,2871,2836$, 1978, 1961, 1905, 1822, 1770, 1731, 1700, 1611, 1558, 1514, 1493, 1452, 1357, 1302, 1250, 1097, 1026, 921, 838, 823, 784, 758, 698. $\mathrm{RMN}$ de ${ }^{1} \mathrm{H}\left(300 \mathrm{MHz}, \mathrm{CDCl}_{3}\right) \delta: 3,80(\mathrm{~s}, 3 \mathrm{H}) ; 4,63$ (s, 2H); 5,43 (s, $2 \mathrm{H}) ; 5,49(\mathrm{~s}, 1 \mathrm{H}) ; 6,89$ (d, 2H, $J=8,5 \mathrm{~Hz}) ; 7,22(\mathrm{~d}, 2 \mathrm{H}, J=8,5 \mathrm{~Hz})$; 7,25-7,36 (m, 10H); 7,41 (s, 1H). RMN de ${ }^{13} \mathrm{C}\left(75 \mathrm{MHz}, \mathrm{CDCl}_{3}\right)$ $\delta: 53,6 ; 55,3 ; 62,5 ; 83,0 ; 114,4 ; 122,2 ; 126,5 ; 127,1 ; 127,5 ; 128,4$; 129,$7 ; 141,6 ; 145,7 ; 159,8$.

\section{4-(metilbenzidrilóxi)-1-(3-metilbenzil)-1H-1,2,3-triazol (4j)}

Sólido branco obtido em $42 \%$ de rendimento $0,106 \mathrm{~g}(0,287 \mathrm{mmol})$ a partir de $0,110 \mathrm{~g}(0,750 \mathrm{mmol})$ de 3-metilbenzilazida, $0,0530 \mathrm{~g}$ $(0,270 \mathrm{mmol})$ de ascorbato de sódio, $0,150 \mathrm{~g}(0,675 \mathrm{mmol})$ do alquino 2 e $0,0340 \mathrm{~g}(0,136 \mathrm{mmol})$ de $\mathrm{CuSO}_{4} \cdot 5 \mathrm{H}_{2} \mathrm{O} . \mathrm{CCD} \mathrm{R}_{\mathrm{f}}=0,51$ (hexano-acetato de etila-diclorometano 3:1:3 v/v). $\mathrm{T}_{\mathrm{f}}: 106,3-106,6{ }^{\circ} \mathrm{C}$. IV (ATR) $\bar{v}_{\text {max }} / \mathrm{cm}^{-1}: 3087,3062,3031,2954,2921,2867,1965,1905$, 1828, 1695, 1598, 1554, 1493, 1454, 1388, 1340, 1307, 1054, 1024, $910,845,771,744,736,702,694$. RMN de ${ }^{1} \mathrm{H}\left(300 \mathrm{MHz}, \mathrm{CDCl}_{3}\right) \delta$ : 2,28 (s, 3H); 4,64 (s, 2H); 5,50-5,51 (m, 3H); 7, 15 (d, 1H, J=7,5 Hz); 7,23-7,32 (m, 14H). RMN de ${ }^{13} \mathrm{C}\left(75 \mathrm{MHz}, \mathrm{CDCl}_{3}\right) \delta: 19,0 ; 52,3$; 62,$5 ; 83,0 ; 122,3 ; 126,6 ; 127,1 ; 127,5 ; 128,4 ; 129,1 ; 129,4 ; 131,0$; 132,$4 ; 136,9 ; 141,6 ; 145,5$.

\section{4-(metilbenzidrilóxi)-1-(4-nitrobenzil)-1H-1,2,3-triazol (4k)}

Sólido amarelo obtido em $84 \%$ de rendimento $(0,226 \mathrm{~g}$; $0,564 \mathrm{mmol})$ a partir de $0,132 \mathrm{~g}(0,741 \mathrm{mmol})$ de 4-nitrobenzilazida, 0,0530 g (0,270 mmol) de ascorbato de sódio, 0,150 g (0,675 mmol) do alquino 2 e $0,0340 \mathrm{~g}(0,136 \mathrm{mmol}) \mathrm{de} \mathrm{CuSO}_{4} \cdot 5 \mathrm{H}_{2} \mathrm{O} . \mathrm{CCD} \mathrm{R}_{\mathrm{f}}=0,38$ (hexano-acetato de etila-diclorometano $3: 1: 3 \mathrm{v} / \mathrm{v}$ ). $\mathrm{T}_{\mathrm{f}}: 104,5-106,3^{\circ} \mathrm{C}$. IV (ATR) $\bar{v}_{\text {max }} / \mathrm{cm}^{-1}: 3131,3081,3027,2921,2865,1965,1895,1814$, 1770, 1601, 1518, 1453, 1425, 1343, 1059, 1020, 919, 851, 733, 699. RMN de ${ }^{1} \mathrm{H}\left(300 \mathrm{MHz}, \mathrm{CDCl}_{3}\right.$ ) $\delta: ~ 4,67$ (s, 2H); 5,51 (s, 1H); 5,60 (s, 2H); 7,21-7,39 (m, 12H); 7,53 (s, 1H); 8,20 (d, 2H, J=8,7 Hz). $\mathrm{RMN}$ de ${ }^{13} \mathrm{C}\left(75 \mathrm{MHz}, \mathrm{CDCl}_{3}\right) \delta: 53,0 ; 62,5 ; 83,3 ; 122,6 ; 124,2$; 127,$0 ; 127,6 ; 128,4 ; 128,6 ; 141,5 ; 141,6 ; 146,4 ; 148,0$.

\section{4-(metilbenzidrilóxi)-1-(4-metilbenzil)-1H-1,2,3-triazol (4l)}

Sólido branco obtido em $88 \%$ de rendimento $(0,196 \mathrm{~g}$; $0,530 \mathrm{mmol})$ a partir de $0,940 \mathrm{~g}(0,710 \mathrm{mmol})$ de 4-metilbenzilazida, 0,0500 g (0,250 mmol) de ascorbato de sódio, 0,140 g (0,630 mmol) do alquino 2 e $0,0320 \mathrm{~g}(0,130 \mathrm{mmol})$ de $\mathrm{CuSO}_{4} \cdot 5 \mathrm{H}_{2} \mathrm{O}$. CCD $\mathrm{R}_{\mathrm{f}}=0,71$ (hexano-acetato de etila-diclorometano 3:1:3 v/v). $\mathrm{T}_{\mathrm{f}}$ : 76,0-77,8 ${ }^{\circ} \mathrm{C}$. IV (ATR) $\overline{\mathrm{v}}_{\max } / \mathrm{cm}^{-1}: 3091,3062,3027,2948,2921$, 2860, 1970, 1897, 1812, 1656, 1596, 1560, 1516, 1491, 1453, 1388, $1105,1055,921,839,743,696$. RMN de ${ }^{1} \mathrm{H}\left(300 \mathrm{MHz}, \mathrm{CDCl}_{3}\right) \delta$ : 2,35 (s, 3H); 4,63 (s, 2H); 5,45 (s, 2H); 5,49 (s, 1H); 7, 17 (sl, 4H); 7,23-7,35 (m, 10H); 7,43 (s, 1H). RMN de ${ }^{13} \mathrm{C}\left(75 \mathrm{MHz}, \mathrm{CDCl}_{3}\right)$ $\delta: 21,1 ; 53,9 ; 62,5 ; 83,0 ; 122,3 ; 127,1 ; 127,5 ; 128,1 ; 128,3 ; 129,7$; 131,$5 ; 138,6 ; 141,6 ; 146,0$.

\section{4-(metilbenzidrilóxi)-1-(4-trifluorometoxibenzil)-1H-1,2,3-triazol (4m)}

Sólido branco obtido em $72 \%$ de rendimento $(0,071 \mathrm{~g}$; $0,161 \mathrm{mmol})$ a partir de $0,054 \mathrm{~g}(0,248 \mathrm{mmol})$ de 4-trifluorometoxibenzilazida, 0,0180 $\mathrm{g}(0,0910 \mathrm{mmol})$ de ascorbato de sódio, 0,0500 $\mathrm{g}$ $(0,225 \mathrm{mmol})$ do alquino 2 e $0,0120 \mathrm{~g}(0,0480 \mathrm{mmol})$ de $\mathrm{CuSO}_{4} \cdot 5 \mathrm{H}_{2} \mathrm{O}$. CCD $\mathrm{R}_{\mathrm{f}}=0,65$ (hexano-acetato de etila-diclorometano 3:1:3 v/v).
$\mathrm{T}_{\mathrm{f}}: 90-90,6^{\circ} \mathrm{C} . \mathrm{IV}$ (ATR) $\overline{\mathrm{v}}_{\text {max }} / \mathrm{cm}^{-1}: 3131,3091,3031,2939,2865$, 1978, 1959, 1897, 1608, 1597, 1510, 1493, 1453, 1254, 1221, 1164, $1055,1024,925,841,793,747,697 . \mathrm{RMN} \mathrm{de}{ }^{1} \mathrm{H}\left(300 \mathrm{MHz}, \mathrm{CDCl}_{3}\right)$ $\delta: ~ 4,66(\mathrm{~s}, 2 \mathrm{H}) ; 5,50(\mathrm{~s}, 3 \mathrm{H}) ; 7,22(\mathrm{~d}, 2 \mathrm{H}, J=8,7 \mathrm{~Hz}) ; 7,26-7,36(\mathrm{~m}$, $12 \mathrm{H}) ; 7,47$ (s, $1 \mathrm{H})$. RMN de ${ }^{13} \mathrm{C}\left(75 \mathrm{MHz}, \mathrm{CDCl}_{3}\right) \delta: 53,2 ; 62,5 ; 83,1$; 121,$5 ; 120,3$ (q, $\left.J_{C-F}=255,8 \mathrm{~Hz}\right) ; 122,4 ; 127,0 ; 127,6 ; 128,4 ; 129,5$; 133,$3 ; 141,6 ; 146,1 ; 149,3$.

\section{4-(metilbenzidrilóxi)-1-(2-nitro-4-(trifluorometilfenil)-1H-1,2,3- triazol (4n)}

Sólido amarelo obtido em $54 \%$ de rendimento $(0,144 \mathrm{~g}$; $0,316 \mathrm{mmol})$ a partir de $0,150 \mathrm{~g}(0,642 \mathrm{mmol})$ de 2-nitro-4-trifluorometilfenilazida, $0,046 \mathrm{~g}(0,233 \mathrm{mmol})$ de ascorbato de sódio, $0,130 \mathrm{~g}$ $(0,584 \mathrm{mmol})$ do alquino 2 e $0,029 \mathrm{~g}(0,116 \mathrm{mmol})$ de $\mathrm{CuSO}_{4} \cdot 5 \mathrm{H}_{2} \mathrm{O}$. $\mathrm{CCD} \mathrm{R}_{\mathrm{f}}=0,66$ (hexano-acetato de etila-diclorometano 3:1:3 v/v). $\mathrm{T}_{\mathrm{f}}$ : $149,2-150,6^{\circ} \mathrm{C}$. IV (ATR) $\overline{\mathrm{v}}_{\max } / \mathrm{cm}^{-1}: 3145,3091,3027,2935,2890$, 2848, 2788, 2000-1660, 1625, 1589, 1546, 1493, 1432, 1321, 1177, $1128,1098,1076,1035,937,898,842,739$. RMN de ${ }^{1} \mathrm{H}(300 \mathrm{MHz}$, $\left.\mathrm{CDCl}_{3}\right) \delta: 4,78(\mathrm{~s}, 2 \mathrm{H}) ; 5,57(\mathrm{~s}, 1 \mathrm{H}) ; 7,40-7,24(\mathrm{~m}, 10 \mathrm{H}) ; 7,79(\mathrm{~d}$, $1 \mathrm{H}, J=8,2 \mathrm{~Hz}$ ); 7,88 (s, 1H), 8,04 (d, $1 \mathrm{H}, J=8,2 \mathrm{~Hz}), 8,32$ (s, 1H). $\mathrm{RMN} \mathrm{de}{ }^{13} \mathrm{C}\left(75 \mathrm{MHz}, \mathrm{CDCl}_{3}\right) \delta: 62,2 ; 83,4 ; 123,1\left(\mathrm{q}, J_{C-F}=3,75 \mathrm{~Hz}\right)$; 123,$7 ; 125,6\left(\mathrm{q}^{*}, J_{C-F}=245,2 \mathrm{~Hz}\right) ; 127,1 ; 127,7 ; 128,4 ; 128,5 ; 130,5$ $\left(\mathrm{q}, J_{C-F}=3,25 \mathrm{~Hz}\right) ; 132,9$ (q, $\left.J_{C-F}=28,5 \mathrm{~Hz}\right) ; 141,4 ; 144,0 ; 146,7$. *No espectro de RMN de ${ }^{13} \mathrm{C}$ não foi possível identificar o sinal do carbono do anel benzênico, pois provavelmente o seu sinal se encontra na região do ruído do equipamento.

\section{Procedimento geral para a obtenção dos derivados 1,2,3-triazólicos da benzofenona $\mathbf{5 a - 5 m}$}

Para a síntese dos compostos triazólicos $\mathbf{5 a - 5 m}$, foi empregado procedimento similar ao descrito para os derivados 4a-4n. Entretanto, foi utilizado como alquino terminal o pent-4-in-ilóxi difenilmetano (3) e o tempo de reação foi de 4 horas. As informações pertinentes às reações envolvidas na preparação dos compostos 5a-5m e os dados que suportam as estruturas destes estão descritos a seguir.

\section{4-(3-propilbenzidrilóxi)-1-benzil-1H-1,2,3-triazol (5a)}

Sólido branco obtido em $70 \%$ de rendimento $(0,100 \mathrm{~g}$; $0,260 \mathrm{mmol})$ a partir de $0,077 \mathrm{~g}(0,580 \mathrm{mmol})$ de benzilazida, $0,042 \mathrm{~g}$ $(0,212 \mathrm{mmol})$ de ascorbato de sódio, $0,132 \mathrm{~g}(0,527 \mathrm{mmol})$ do alquino 3 e $0,026 \mathrm{~g}(0,108 \mathrm{mmol})$ de $\mathrm{CuSO}_{4} \cdot 5 \mathrm{H}_{2} \mathrm{O}$. CCD R $\mathrm{f}=0,52$ (hexano-acetato de etila-diclorometano 3:1:3 v/v). $\mathrm{T}_{\mathrm{f}}: 83,4-84,1^{\circ} \mathrm{C}$. IV (ATR) $\overline{\mathrm{v}}_{\max } / \mathrm{cm}^{-1}:$ 3112, 3061, 3027, 2940, 2912, 2894, 2858, 2000-1660, $1599,1543,1493,1448,1103,916 . \mathrm{RMN}$ de ${ }^{1} \mathrm{H}\left(300 \mathrm{MHz}, \mathrm{CDCl}_{3}\right)$ $\delta$ : 2,00 (quint, $2 \mathrm{H}, J=6,8 \mathrm{~Hz}) ; 2,84(\mathrm{t}, 2 \mathrm{H}, J=7,5 \mathrm{~Hz}) ; 3,48(\mathrm{t}, 2 \mathrm{H}$, $J=6,1 \mathrm{~Hz}) ; 5,30(\mathrm{~s}, 1 \mathrm{H}) ; 5,44(\mathrm{~s}, 2 \mathrm{H}) ; 7,08(\mathrm{~s}, 1 \mathrm{H}) ; 7,37-7,21(\mathrm{~m}$, 15H). RMN de ${ }^{13} \mathrm{C}\left(75 \mathrm{MHz}, \mathrm{CDCl}_{3}\right) \delta: 22,5 ; 29,4 ; 53,9 ; 67,9 ; 83,5$; 120,$8 ; 126,9 ; 127,3 ; 127,9 ; 128,3 ; 128,5 ; 129,0 ; 134,9 ; 142,4 ; 148,1$.

\section{4-(3-propilbenzidrilóxi)-1-(4-bromobenzyl)-1H-1,2,3-triazol (5b)}

Sólido branco obtido em $42 \%$ de rendimento $(0,116 \mathrm{~g}$; $0,250 \mathrm{mmol})$ a partir de $0,139 \mathrm{~g}(0,659 \mathrm{mmol})$ de 4-bromobenzilazida, $0,047 \mathrm{~g}(0,239 \mathrm{mmol})$ de ascorbato de sódio, 0,150 g (0,599 mmol) do alquino 3 e $0,030 \mathrm{~g}(0,119 \mathrm{mmol})$ de $\mathrm{CuSO}_{4} \cdot 5 \mathrm{H}_{2} \mathrm{O}$. CCD R $\mathrm{R}_{\mathrm{f}}=0,58$ (hexano-acetato de etila-diclorometano 3:1:3 v/v). $\mathrm{T}_{\mathrm{f}}: 94,6-95,2^{\circ} \mathrm{C}$. IV (ATR) $\bar{v}_{\text {max }} / \mathrm{cm}^{-1}: 3106,3077,3056,3023,2944,2921,2867,2852$, 2000-1660, 1596, 1544, 1489, 1456, 1404, 1187, 1067, 1103, 916, 808, 741, 698, 485. RMN de ${ }^{1} \mathrm{H}\left(300 \mathrm{MHz}, \mathrm{CDCl}_{3}\right) \delta$ : 1,99 (quint, $2 \mathrm{H}, J=6,8 \mathrm{~Hz}) ; 2,84$ (t, 2H, $J=7,5 \mathrm{~Hz}) ; 3,47$ (t, 2H, $J=6,0 \mathrm{~Hz}$ ); 5,29 (s, 1H); 5,38 (s, 2H); 7,09-7,06 (m, 3H); 7,33-7,22 (m, 10H); $7,48(\mathrm{~d}, 2 \mathrm{H}, J=8,1 \mathrm{~Hz})$. RMN de ${ }^{13} \mathrm{C}\left(75 \mathrm{MHz}, \mathrm{CDCl}_{3}\right) \delta: 22,4 ; 29,3$; 53,$2 ; 67,9 ; 83,5 ; 120,7 ; 122,7 ; 126,9 ; 127,3 ; 128,3 ; 129,5 ; 132,2$; 133,$9 ; 142,3 ; 148,3$. 
4-(3-propilbenzidrilóxi)-1-(4-fluorobenzil)-1H-1,2,3-triazol (5c)

Sólido branco obtido em $49 \%$ de rendimento $(0,103 \mathrm{~g}$; $0,256 \mathrm{mmol})$ a partir de $0,086 \mathrm{~g}(0,571 \mathrm{mmol})$ de 4-fluorobenzilazida, $0,041 \mathrm{~g}(0,208 \mathrm{mmol})$ de ascorbato de sódio, $0,130 \mathrm{~g}(0,519 \mathrm{mmol})$ do alquino 3 e $0,026 \mathrm{~g}(0,104 \mathrm{mmol})$ de $\mathrm{CuSO}_{4} \cdot 5 \mathrm{H}_{2} \mathrm{O} . \mathrm{CCD} \mathrm{R} \mathrm{f}_{\mathrm{f}}=0,51$ (hexano-acetato de etila-diclorometano 3:1:3 v/v). $\mathrm{T}_{\mathrm{f}}: 69,4-70,1^{\circ} \mathrm{C}$. IV (ATR) $\overline{\mathrm{v}}_{\max } / \mathrm{cm}^{-1}: 3120,3068,3027,2954,2929,2890,2856$, 2000-1660, 1600, 1547, 1508, 1494, 1445, 1398, 1158, 1053, 917, $831,739,694$. RMN de ${ }^{1} \mathrm{H}\left(300 \mathrm{MHz}, \mathrm{CDCl}_{3}\right) \delta: 1,99$ (quint, $2 \mathrm{H}$, $J=6,8 \mathrm{~Hz}) ; 2,84(\mathrm{t}, 2 \mathrm{H}, J=7,5 \mathrm{~Hz}) ; 3,48(\mathrm{t}, 2 \mathrm{H}, J=6,0 \mathrm{~Hz}) ; 5,30$ (s, 1H); 5,40 (s, 2H); 7,07-7,01 (m, 3H); 7,33-7,18 (m, 12H). RMN de ${ }^{13} \mathrm{C}\left(75 \mathrm{MHz}, \mathrm{CDCl}_{3}\right) \delta: 22,4 ; 29,4 ; 53,1 ; 67,9 ; 83,6 ; 116,0(\mathrm{~d}$, $\left.J_{C-F}=21,7 \mathrm{~Hz}\right) ; 120,7 ; 126,9 ; 127,3 ; 128,3 ; 129,7\left(\mathrm{~d}, J_{C-F}=8,2 \mathrm{~Hz}\right)$; $130,7\left(\mathrm{~d}, J_{C-F}=3,7 \mathrm{~Hz}\right) ; 162,7\left(\mathrm{~d}, J_{C-F}=246,7 \mathrm{~Hz}\right)$.

\section{4-(3-propilbenzidrilóxi)-1-(4-clorobenzil)-1H-1,2,3-triazol (5d)}

Sólido branco obtido em $70 \%$ de rendimento $(0,165 \mathrm{~g}$; $0,423 \mathrm{mmol})$ a partir de $0,111 \mathrm{~g}(0,667 \mathrm{mmol})$ de 4-clorobenzilazida, $0,048 \mathrm{~g}(0,243 \mathrm{mmol})$ de ascorbato de sódio, 0,152 g (0,607 mmol) do alquino 3 e $0,030 \mathrm{~g}(0,121 \mathrm{mmol})$ de $\mathrm{CuSO}_{4} \cdot 5 \mathrm{H}_{2} \mathrm{O} . \mathrm{CCD} \mathrm{R}_{\mathrm{f}}=0,28$ (hexano-acetato de etila-diclorometano 3:1:3 v/v). $\mathrm{T}_{\mathrm{f}}: 92,6-93,3^{\circ} \mathrm{C}$. IV (ATR) $\overline{\mathrm{v}}_{\max } / \mathrm{cm}^{-1}: 3106,3077,3056,3023,3002,2945,2925$, 2869, 2777, 2000-1660, 1596, 1544, 1492, 1446, 1322, 1188, 1064, $1103,916,853,810,741,699,491 . \mathrm{RMN}$ de ${ }^{1} \mathrm{H}\left(300 \mathrm{MHz}, \mathrm{CDCl}_{3}\right)$ $\delta: 2,00$ (quint, $2 \mathrm{H}, J=6,8 \mathrm{~Hz}) ; 2,84(\mathrm{t}, 2 \mathrm{H}, J=7,6 \mathrm{~Hz}) ; 3,48(\mathrm{t}, 2 \mathrm{H}$, $J=6,0 \mathrm{~Hz}) ; 5,29(\mathrm{~s}, 1 \mathrm{H}) ; 5,39(\mathrm{~s}, 2 \mathrm{H}) ; 7,07(\mathrm{~s}, 1 \mathrm{H}) ; 7,13(\mathrm{~d}, 2 \mathrm{H}$, $J=8,4 \mathrm{~Hz}) ; 7,33-7,22(\mathrm{~m}, 12 \mathrm{H})$. RMN de ${ }^{13} \mathrm{C}\left(75 \mathrm{MHz}, \mathrm{CDCl}_{3}\right) \delta$ : 22,$4 ; 29,3 ; 53,1 ; 67,9 ; 83,5 ; 120,7 ; 126,9 ; 127,3 ; 128,3 ; 129,2 ; 133,4$; 134,$6 ; 142,4 ; 148,3$.

4-(3-propilbenzidrilóxi)-1-(4-trifluorometilbenzil)-1H-1,2,3-triazol (5e)

Sólido branco obtido em $37 \%$ de rendimento $(0,087 \mathrm{~g}$; $0,192 \mathrm{mmol})$ a partir de $0,114 \mathrm{~g}(0,570 \mathrm{mmol})$ de 4-trifluorobenzilazida, 0,041 g (0,208 $\mathrm{mmol})$ de ascorbato de sódio, 0,130 g (0,519 mmol $)$ do alquino 3 e $0,026 \mathrm{~g}(0,104 \mathrm{mmol})$ de $\mathrm{CuSO}_{4} \cdot 5 \mathrm{H}_{2} \mathrm{O} . \mathrm{CCD} \mathrm{R} \mathrm{f}_{\mathrm{f}}=0,30$ (hexano-acetato de etila-diclorometano 3:1:3 v/v). $\mathrm{T}_{\mathrm{f}}: 64,6-65,2^{\circ} \mathrm{C}$. IV (ATR) $\overline{\mathrm{v}}_{\text {max }} / \mathrm{cm}^{-1}: 3120,3065,3031,2938,2856,2000-1660,1616$, $1598,1555,1494,1447,1421,1324,1268,1160,1104,918,820$, 753, 737, 696. RMN de ${ }^{1} \mathrm{H}\left(300 \mathrm{MHz}, \mathrm{CDCl}_{3}\right) \delta: 2,01$ (quint, $2 \mathrm{H}$, $J=6,7 \mathrm{~Hz}) ; 2,86(\mathrm{t}, 2 \mathrm{H}, J=7,5 \mathrm{~Hz}) ; 3,48(\mathrm{t}, 2 \mathrm{H}, J=6,0 \mathrm{~Hz}) ; 5,30$ (s, 1H); 5,49 (s, 2H); 7,10 (s, 1H); 7,33-7,22 (m, 12H); 7,61 (d, 2H, $J=8,1 \mathrm{~Hz})$. RMN de ${ }^{13} \mathrm{C}\left(75 \mathrm{MHz}, \mathrm{CDCl}_{3}\right) \delta: 22,4 ; 29,3 ; 53,2 ; 67,9$; 83,$5 ; 120,9 ; 125,9$ (q, $\left.J_{C-F}=3,7 \mathrm{~Hz}\right) ; 126,9 ; 127,3 ; 128,0 ; 128,3$; $123,7\left(\mathrm{q}, J_{C-F}=272,2 \mathrm{~Hz}\right) ; 130,8\left(\mathrm{q}, J_{C-F}=32,2 \mathrm{~Hz}\right)$.

\section{4-(3-propilbenzidrilóxi)-1-(2-bromobenzil)-1H-1,2,3-triazol (5f)}

Óleo incolor obtido em $55,6 \%$ de rendimento $(0,128 \mathrm{~g}$; $0,276 \mathrm{mmol})$ a partir de $0,116 \mathrm{~g}(0,549 \mathrm{mmol})$ de 2-bromobenzilazida, $0,040 \mathrm{~g}(0,200 \mathrm{mmol})$ de ascorbato de sódio, 0,125 g (0,499 mmol) do alquino 3 e $0,025 \mathrm{~g}(0,100 \mathrm{mmol})$ de $\mathrm{CuSO}_{4} \cdot 5 \mathrm{H}_{2} \mathrm{O}$. CCD R $\mathrm{R}_{\mathrm{f}}=0,52$ (hexano-acetato de etila-diclorometano 3:1:3 v/v). IV (ATR) $\overline{\mathrm{v}}_{\max } / \mathrm{cm}^{-1}:$ 3139, 3062, 3027, 2926, 2856, 2000-1660, 1598, 1548, 1493, 1444, 1356, 1098, 1069, 922, 788, 743, 698, 653. RMN de ${ }^{1} \mathrm{H}\left(300 \mathrm{MHz}, \mathrm{CDCl}_{3}\right) \delta: 2,00$ (quint, $2 \mathrm{H}, J=6,9 \mathrm{~Hz}$ ); 2,85 (t, 2H, $J=7,6 \mathrm{~Hz}) ; 3,48(\mathrm{t}, 2 \mathrm{H}, J=6,1 \mathrm{~Hz}) ; 5,29(\mathrm{~s}, 1 \mathrm{H}) ; 5,57$ (s, 2H); 7,05 (d, $1 \mathrm{H}, J=7,2 \mathrm{~Hz}) ; 7,33-7,18$ (m, 13H); 7,60 (d, 1H, $J=7,8 \mathrm{~Hz})$. RMN de ${ }^{13} \mathrm{C}\left(75 \mathrm{MHz}, \mathrm{CDCl}_{3}\right) \delta: 22,4 ; 29,4 ; 53,5 ; 67,9 ; 83,6 ; 121,1 ; 123,1$; 126,$9 ; 127,3 ; 128,1 ; 128,2 ; 130,0 ; 130,1 ; 133,0 ; 134,4 ; 142,3 ; 148,0$.

\section{4-(3-propilbenzidrilóxi)-1-(4-iodobenzil)-1H-1,2,3-triazol (5g)}

Sólido branco obtido em $56 \%$ de rendimento $(0,090 \mathrm{~g}$; $0,176 \mathrm{mmol})$ a partir de $0,089 \mathrm{~g}(0,347 \mathrm{mmol})$ de 4 -iodobenzilazida,
0,021 $\mathrm{g}(0,126 \mathrm{mmol})$ de ascorbato de sódio, 0,079 $\mathrm{g}(0,315 \mathrm{mmol}) \mathrm{do}$ alquino 3 e $0,0157 \mathrm{~g}(0,063 \mathrm{mmol})$ de $\mathrm{CuSO}_{4} \cdot 5 \mathrm{H}_{2} \mathrm{O} \cdot \mathrm{CCD} \mathrm{R} \mathrm{R}_{\mathrm{f}}=0,50$ (hexano-acetato de etila-diclorometano 3:1:3 v/v). $\mathrm{T}_{\mathrm{f}}: 101,2-101,6^{\circ} \mathrm{C}$. IV (ATR) $\overline{\mathrm{V}}_{\max } / \mathrm{cm}^{-1}: 3129,3106,3081,3026,2944,2921,2877,2856$, 2777, 2000-1660, 1592, 1544, 1485, 1455, 1351, 1102, 1052, 916, $813,740,695,614$. RMN de ${ }^{1} \mathrm{H}\left(300 \mathrm{MHz}, \mathrm{CDCl}_{3}\right) \delta: 2,00$ (quint, $2 \mathrm{H}$, $J=6,8 \mathrm{~Hz}) ; 2,84$ (t, 2H, $J=7,5 \mathrm{~Hz}) ; 3,47$ (t, 2H, $J=6,0 \mathrm{~Hz}) ; 5,30$ (s, $1 \mathrm{H}) ; 5,38$ (s, 2H); 6,95 (d, 2H, $J=7,9 \mathrm{~Hz}) ; 7,07$ (s, 1H); 7,33-7,23 $(\mathrm{m}, 10 \mathrm{H}) ; 7,69(\mathrm{~d}, 2 \mathrm{H}, J=7,9 \mathrm{~Hz})$. RMN de ${ }^{13} \mathrm{C}\left(75 \mathrm{MHz}, \mathrm{CDCl}_{3}\right) \delta$ : 22,$4 ; 29,3 ; 53,3 ; 67,9 ; 83,5 ; 94,3 ; 120,7 ; 126,9 ; 127,3 ; 128,3 ; 129,6$; 134,$6 ; 138,1 ; 142,4 ; 148,3$.

4-(3-propilbenzidrilóxi)-1-(4-isopropilbenzil)-1H-1,2,3-triazol (5h) Sólido branco obtido em $61 \%$ de rendimento $(0,120 \mathrm{~g}$; $0,282 \mathrm{mmol})$ a partir de $0,089 \mathrm{~g}(0,510 \mathrm{mmol})$ de 4-isopropilbenzilazida, 0,0365 $\mathrm{g}(0,185 \mathrm{mmol})$ de ascorbato de sódio, 0,116 $\mathrm{g}$ $(0,463 \mathrm{mmol})$ do alquino 3 e $0,023 \mathrm{~g}(0,093 \mathrm{mmol})$ de $\mathrm{CuSO}_{4} \cdot 5 \mathrm{H}_{2} \mathrm{O}$. CCD $\mathrm{R}_{\mathrm{f}}=0,54$ (hexano-acetato de etila-diclorometano 3:1:3 v/v). $\mathrm{T}_{\mathrm{f}}: 77,7-77,5^{\circ} \mathrm{C}$. IV (ATR) $\overline{\mathrm{v}}_{\max } / \mathrm{cm}^{-1}: 3129,3087,3056,3031,2953$, 2868, 2769, 2000-1660, 1598, 1555, 1510, 1493, 1448, 1102, 1072, $1049,925,783,739,696 . \mathrm{RMN}$ de ${ }^{1} \mathrm{H}\left(300 \mathrm{MHz}, \mathrm{CDCl}_{3}\right) \delta: 1,24$ (d, $6 \mathrm{H}, J=6,9 \mathrm{~Hz}$ ); 1,99 (quint, $2 \mathrm{H}, J=6,6 \mathrm{~Hz}) ; 2,83(\mathrm{t}, 2 \mathrm{H}, J=7,6 \mathrm{~Hz}$ ); 2,96-2,89 (m, 1H); 3,48 (t, 2H, $J=6,0 \mathrm{~Hz}) ; 5,30(\mathrm{~s}, 1 \mathrm{H}) ; 5,40$ (s, $2 \mathrm{H}) ; 7,07$ (s, 1H); 7,15 (d, 2H, $J=8,1) ; 7,33-7,21$ (m, 12H). RMN de ${ }^{13} \mathrm{C}\left(75 \mathrm{MHz}, \mathrm{CDCl}_{3}\right) \delta: 22,5 ; 23,9 ; 29,4 ; 33,8 ; 53,7 ; 67,9 ; 83,5$; 120,$7 ; 126,9 ; 127,0 ; 127,3 ; 128,0 ; 128,3 ; 148,0 ; 149,4$.

\section{4-(3-propilbenzidrilóxi)-1-(4-metoxibenzil)-1H-1,2,3-triazol (5i)}

Sólido branco obtido em $57 \%$ de rendimento $(0,142 \mathrm{~g}$; $0,343 \mathrm{mmol})$ a partir de $0,107 \mathrm{~g}(0,658 \mathrm{mmol})$ de 4-metoxibenzilazida, 0,047 g (0,239 mmol) de ascorbato de sódio, 0,150 g (0,599 mmol) do alquino 3 e $0,029 \mathrm{~g}(0,119 \mathrm{mmol})$ de $\mathrm{CuSO}_{4} \cdot 5 \mathrm{H}_{2} \mathrm{O}$. CCD R $\mathrm{R}_{\mathrm{f}}=0,41$ (hexano-acetato de etila-diclorometano $3: 1: 3 \mathrm{v} / \mathrm{v}$ ). $\mathrm{T}_{\mathrm{f}}: 83,6-84,3{ }^{\circ} \mathrm{C}$. IV (ATR) $\bar{v}_{\max } / \mathrm{cm}^{-1}: 3112,3081,3021,3004,2947,2871,2848$, 2000-1660, 1610, 1583, 1544, 1514, 1493, 1454, 1396, 1103, 1064, 916, 833, 741, 697. RMN de ${ }^{1} \mathrm{H}\left(300 \mathrm{MHz}, \mathrm{CDCl}_{3}\right) \delta: 1,98$ (quint, $2 \mathrm{H}, J=6,7 \mathrm{~Hz}) ; 2,82(\mathrm{t}, 2 \mathrm{H}, J=7,5 \mathrm{~Hz}) ; 3,47$ (t, 2H, $J=6,0 \mathrm{~Hz})$; $3,80$ (s, 3H); 5,29 (s, 1H); 5,37 (s, 2H); 6,88 (d, 2H, $J=8,4 \mathrm{~Hz}) ; 7,05$ (s, $1 \mathrm{H}) ; 7,18$ (d, 2H, $J=8,4 \mathrm{~Hz}) ; 7,31-7,22(\mathrm{~m}, 10 \mathrm{H})$. RMN de ${ }^{13} \mathrm{C}$ $\left(75 \mathrm{MHz}, \mathrm{CDCl}_{3}\right) \delta: 22,5 ; 29,4 ; 53,4 ; 55,3 ; 67,9 ; 83,5 ; 114,3 ; 120,5$; 126,$9 ; 127,3 ; 128,3 ; 129,5 ; 142,4 ; 148,0,159,7$.

Não foi possível observar no espectro de $\mathrm{RMN}$ de ${ }^{13} \mathrm{C}$ o sinal do carbono aromático ligado ao carbono metileno, pois devido à baixa intensidade do sinal, o mesmo possivelmente se encontra na região do ruído do equipamento.

\section{4-(3-(propilbenzidrilóxi)-1-(3-metilbenzil)-1H-1,2,3-triazol (5j)}

Sólido branco obtido em $52 \%$ de rendimento $(0,100 \mathrm{~g}$; $0,251 \mathrm{mmol})$ a partir de $0,090 \mathrm{~g}(0,616 \mathrm{mmol})$ de 3-metilbenzilazida, $0,044 \mathrm{~g}(0,224 \mathrm{mmol})$ de ascorbato de sódio, 0,120 g (0,480 mmol) do alquino 3 e $0,028 \mathrm{~g}(0,112 \mathrm{mmol})$ de $\mathrm{CuSO}_{4} \cdot 5 \mathrm{H}_{2} \mathrm{O} \cdot \mathrm{CCD} \mathrm{R}_{\mathrm{f}}=0,50$ (hexano-acetato de etila-diclorometano $3: 1: 3 \mathrm{v} / \mathrm{v}$ ). $\mathrm{T}_{\mathrm{f}}: 57,9-58,8^{\circ} \mathrm{C}$. IV (ATR) $\bar{v}_{\max } / \mathrm{cm}^{-1}: 3131,3081,3066,3021,2950,2929,2890$, 2861, 2769, 2000-1660, 1598, 1547, 1493, 1454, 1396, 1106, 1067, 836, 740, 696. RMN de ${ }^{1} \mathrm{H}\left(300 \mathrm{MHz}, \mathrm{CDCl}_{3}\right.$ ) $\delta: 1,98$ (quint, $2 \mathrm{H}$, $J=6,9 \mathrm{~Hz}) ; 2,25(\mathrm{~s}, 3 \mathrm{H}) ; 2,28(\mathrm{t}, 2 \mathrm{H}, J=7,6 \mathrm{~Hz}) ; 3,47(\mathrm{t}, 2 \mathrm{H}$, $J=6,1 \mathrm{~Hz}) ; 5,29(\mathrm{~s}, 1 \mathrm{H}) ; 5,45(\mathrm{~s}, 2 \mathrm{H}) ; 6,98(\mathrm{~s}, 1 \mathrm{H}) ; 7,08(\mathrm{~d}, 1 \mathrm{H}$, $J=6,9 \mathrm{~Hz}) ; 7,33-7,19(\mathrm{~m}, 13 \mathrm{H})$. RMN de ${ }^{13} \mathrm{C}\left(75 \mathrm{MHz}, \mathrm{CDCl}_{3}\right) \delta$ : 18,$9 ; 22,5 ; 29,4 ; 52,1 ; 68,0 ; 83,5 ; 120,5 ; 126,5 ; 126,9 ; 127,3 ; 128,2$; 128,$9 ; 129,2 ; 130,9 ; 132,8 ; 136,8 ; 142,4 ; 147,9$.

4-(3-propilbenzidrilóxi)-1-(4-metilbenzil)-1H-1,2,3-triazol (5k) Sólido branco obtido em $77 \%$ de rendimento $(0,135 \mathrm{~g}$; 
$0,339 \mathrm{mmol})$ a partir de $0,071 \mathrm{~g}(0,487 \mathrm{mmol})$ de 3 -metilbenzilazida, $0,035 \mathrm{~g}(0,177 \mathrm{mmol})$ de ascorbato de sódio, $0,111 \mathrm{~g}(0,443 \mathrm{mmol})$ do alquino 3 e $0,022 \mathrm{~g}(0,088 \mathrm{mmol})$ de $\mathrm{CuSO}_{4} \cdot 5 \mathrm{H}_{2} \mathrm{O} . \mathrm{CCD} \mathrm{R} \mathrm{R}_{\mathrm{f}}=0,51$ (hexano-acetato de etila-diclorometano 3:1:3 v/v). $\mathrm{T}_{\mathrm{f}}: 102,2-103,0^{\circ} \mathrm{C}$. IV (ATR) $\bar{v}_{\max } / \mathrm{cm}^{-1}: 3126,3081,3023,2948,2921,2871,2852$, 2000-1660, 1598, 1545, 1516, 1493, 1446, 1392, 1105, 1071, 1052, 917, 832, 741, 698. RMN de ${ }^{1} \mathrm{H}\left(300 \mathrm{MHz}, \mathrm{CDCl}_{3}\right) \delta: 1,99$ (quint, $2 \mathrm{H}, J=6,8 \mathrm{~Hz}) ; 2,36(\mathrm{~s}, 3 \mathrm{H}) ; 2,83(\mathrm{t}, 2 \mathrm{H}, J=7,5 \mathrm{~Hz}) ; 3,48(\mathrm{t}, 2 \mathrm{H}$, $J=6,1 \mathrm{~Hz}) ; 5,30(\mathrm{~s}, 1 \mathrm{H}) ; 5,40(\mathrm{~s}, 2 \mathrm{H}) ; 7,06(\mathrm{~s}, 1 \mathrm{H}) ; 7,34-7,11(\mathrm{~m}$, $14 \mathrm{H})$. RMN de ${ }^{13} \mathrm{C}\left(75 \mathrm{MHz}, \mathrm{CDCl}_{3}\right) \delta: 22,5 ; 29,4 ; 53,7 ; 67,9 ; 83,5$; 83,$5 ; 120,6 ; 126,9 ; 127,3 ; 128,0 ; 128,3 ; 129,6 ; 131,9 ; 138,4 ; 142,4$; 148,0 .

\section{4-(propilbenzidrilóxi)-1-(4-trifluorometoxibenzil)-1H-1,2,3-triazol} (5l)

Sólido branco obtido em $59 \%$ de rendimento $(0,132 \mathrm{~g}$; $0,282 \mathrm{mmol})$ a partir de $0,114 \mathrm{~g}(0,527 \mathrm{mmol})$ de 4-trifluorometoxibenzilazida, $0,037 \mathrm{~g}(0,191 \mathrm{mmol})$ de ascorbato de sódio, $0,120 \mathrm{~g}$ $(0,479 \mathrm{mmol})$ do alquino $3 \mathrm{e} 0,024 \mathrm{~g}(0,096 \mathrm{mmol})$ de $\mathrm{CuSO}_{4} \cdot 5 \mathrm{H}_{2} \mathrm{O}$. CCD $\mathrm{R}_{\mathrm{f}}=0,48$ (hexano-acetato de etila-diclorometano 3:1:3 v/v). $\mathrm{T}_{\mathrm{f}}: 76,3-77,5^{\circ} \mathrm{C}$. IV (ATR) $\overline{\mathrm{v}}_{\max } / \mathrm{cm}^{-1}: 3131,3066,3031,2929$, 2848, 2000-1660, 1596, 1548, 1509, 1493, 1453, 1258, 1217, 1157, $1101,1071,928,826,740,696$. RMN de ${ }^{1} \mathrm{H}\left(300 \mathrm{MHz}, \mathrm{CDCl}_{3}\right) \delta$ : 2,00 (quint, $2 \mathrm{H}, J=6,7 \mathrm{~Hz}$ ); 2,85 (t, $2 \mathrm{H}, J=7,6 \mathrm{~Hz}$ ); 3,48 (t, $2 \mathrm{H}$, $J=6,1 \mathrm{~Hz}) ; 5,30(\mathrm{~s}, 1 \mathrm{H}) ; 5,44$ (s, 2H); 7,09 (s, 1H); 7,34-7,19 (m, $14 \mathrm{H})$. RMN de ${ }^{13} \mathrm{C}\left(75 \mathrm{MHz}, \mathrm{CDCl}_{3}\right) \delta: 22,4 ; 29,3 ; 53,0 ; 67,9 ; 83,5$; $118,6\left(\mathrm{q}, J_{C-F}=256,1 \mathrm{~Hz}\right) ; 120,8 ; 121,4 ; 126,9 ; 127,3 ; 128,3 ; 129,3$; 133,$6 ; 142,3 ; 148,3 ; 149,3$.

\section{4-(3-propilbenzidrilóxi)-1-(2-nitro-4-trifluorometilfenil)-1H-1,2,3- triazol $(\mathbf{5 m})$}

Sólido amarelo obtido em $70 \%$ de rendimento $(0,135 \mathrm{~g}$; 0,279 $\mathrm{mmol})$ a partir de 0,101 $\mathrm{g}(0,439 \mathrm{mmol})$ de 2-nitro-4-trifluorometilfenilazida, $0,031 \mathrm{~g}(0,160 \mathrm{mmol})$ de ascorbato de sódio, $0,100 \mathrm{~g}(0,399 \mathrm{mmol})$ do alquino 3 e $0,020 \mathrm{~g}(0,080 \mathrm{mmol}) \mathrm{de}$ $\mathrm{CuSO}_{4} \cdot 5 \mathrm{H}_{2} \mathrm{O} . \mathrm{CCD} \mathrm{R}_{\mathrm{f}}=0,52$ (hexano-acetato de etila-diclorometano 3:1:3 v/v). $\mathrm{T}_{\mathrm{f}}: 96,0-97,0{ }^{\circ} \mathrm{C}$. IV (ATR) $\overline{\mathrm{v}}_{\max } / \mathrm{cm}^{-1}: 3166,3081,3062$, 3031, 2964, 2915, 2861, 2000-1660; 1628, 1592, 1544, 1523, 1493 , $1452,1326,1133,1101,1041,916,897,848,752,735,693 . \mathrm{RMN}$ de ${ }^{1} \mathrm{H}\left(300 \mathrm{MHz}, \mathrm{CDCl}_{3}\right) \delta: 2,09$ (quint, $\left.2 \mathrm{H}, J=6,7 \mathrm{~Hz}\right) ; 2,98(\mathrm{t}$, $2 \mathrm{H}, J=7,3 \mathrm{~Hz}) ; 3,56(\mathrm{t}, 2 \mathrm{H}, J=6,0 \mathrm{~Hz}) ; 5,35(\mathrm{~s}, 1 \mathrm{H}) ; 7,37-7,19(\mathrm{~m}$, $10 \mathrm{H}) ; 7,46$ (s, 1H); 7,69 (d, 1H, $J=8,4 \mathrm{~Hz}) ; 7,99$ (d, 1H, $J=8,4 \mathrm{~Hz})$; $8,28$ (s, $1 \mathrm{H})$. RMN de ${ }^{13} \mathrm{C}\left(75 \mathrm{MHz}, \mathrm{CDCl}_{3}\right) \delta: 22,3 ; 29,1 ; 67,7 ; 83,6$; $120,4\left(\mathrm{q}, J_{C-F}=271,5 \mathrm{~Hz}\right) ; 122,0 ; 122,9\left(\mathrm{q}, J_{C-F}=3,7 \mathrm{~Hz}\right) ; 126,9$; 127,$3 ; 128,1 ; 128,3 ; 130,3\left(\mathrm{q}, J_{C-F}=3,7 \mathrm{~Hz}\right), 132,5\left(\mathrm{q}, J_{C-F}=35,2 \mathrm{~Hz}\right)$, 132,$9 ; 142,3 ; 143,9 ; 148,8$.

\section{Avaliação da atividade fotoprotetora}

A atividade fotoprotetora dos compostos $\mathbf{4 a - 4 n}$ e $\mathbf{5 a - 5 m}$ foi avaliada segundo metodologia desenvolvida por Mansur e colaboradores ${ }^{23}$ utilizando-se espectroscopia no ultravioleta. Determinou-se ainda a atividade fotoprotetora do padrão comercial benzofenona-3. A eficiência dos compostos foi determinada em função de seu fator de proteção solar (FPS). Inicialmente as soluções foram diluídas em etanol até atingir a concentração final de $3,0 \times 10^{-4} \mathrm{~mol} \mathrm{~L}^{-1}$. Cada análise foi realizada em triplicata e as médias das repetições (absorbâncias) foram determinadas na faixa de interesse no espectrofotômetro
(290-320 nm), com intervalos de $5 \mathrm{~nm}$. Foi utilizado o álcool etílico $96 \%$ v/v como branco. Por fim, foi calculado o fator de proteção solar de cada composto. Para realização desses cálculos foi necessário medir as absorbâncias das soluções preparadas em diferentes comprimentos de onda $(290,295,300,305,310,315$, e 320) e posteriormente o fator de proteção solar (FPS) foi calculado utilizando-se a equação mostrada a seguir. ${ }^{12}$

$$
F P S=F C \sum_{290}^{320} E E(\lambda) I(\lambda) a b s(\lambda)
$$

sendo: $\mathrm{FC}=$ Fator de correção (igual a 10$)$; $\mathrm{EE}(\lambda)=$ Efeito eritematogênico da radiação de comprimento de onda $(\lambda)$; $(\lambda)=$ Intensidade da luz solar no comprimento de onda; abs $(\lambda)=$ Absorbância da solução do filtro solar no comprimento de onda $(\lambda)$.

Os valores de $\operatorname{EE}(\lambda) \times \mathrm{I}(\lambda)$, apresentados na Tabela 1 , foram previamente calculados por Sayre e colaboradores. ${ }^{24}$

Cumpre ressaltar que segundo a $\mathrm{RDC}^{\circ} 30$ de 1 de junho de 2012 os métodos preconizados para a determinação do (FPS) são métodos in vivo. Porém, na fase de desenvolvimento da formulação de fotoprotetores, pode-se utilizar métodos in vitro para avaliar o FPS. ${ }^{25,26}$

\section{Cultivo celular e avaliação da atividade citotóxica dos compostos 4a-4n e 5a-5m}

As linhagens celulares utilizadas para avaliação da citotoxicidade foram MDA-MB-231 (adenocarcinoma de mama) e B16F10 (melanoma metastático murino). A linhagem MDA-MB-231 foi gentilmente cedida pela Dra. Sandra Martha Gomes Dias (Laboratório Nacional de Biociências, Campinas, São Paulo, Brasil) e a linhagem B16F10 foi gentilmente cedida pela Dra. Anésia Aparecida dos Santos (Departamento de Biologia Geral, Universidade Federal de Viçosa, Minas Gerais, Brasil). Para o cultivo utilizou-se meio RPMI 1640 (Roswell Park Memorial Institute Medium, Sigma) pH 7,2 suplementado com $100 \mathrm{U} \mathrm{mL}^{-1}$ de penicilina (Sigma), $100 \mu \mathrm{g} \mathrm{mL} \mathrm{mL}^{-1} \mathrm{de}$ estreptomicina (Sigma) e 10\% v/v de soro fetal bovino (SFB, LGC Bio). As células foram crescidas em suspensão utilizando garrafas de 75,150 e $300 \mathrm{~cm}^{2}$, mantidas em atmosfera com $95 \%$ de umidade e $5 \%$ de $\mathrm{CO}_{2}$.

Para avaliação da atividade citotóxica dos compostos, as células foram contadas em câmaras de neubauer, ressuspendidas em meio RPMI 1640 (10\% v/v SFB, $100 \mathrm{U} \mathrm{mL}^{-1}$ de penicilina e $100 \mu \mathrm{g} \mathrm{mL}^{-1}$ de estreptomicina) e incubadas em placa de 96 poços de fundo chato, na densidade de 10.000 células/poço (B16F10) e 25.000 células/poço (MDA-MB-231), mantidas por 24 horas a 37 ${ }^{\circ} \mathrm{C}$ e $5 \%$ de $\mathrm{CO}_{2}$ para adaptação das células. Os compostos foram avaliados nas concentrações de 50 e $100 \mu \mathrm{mol} \mathrm{L}^{-1}$ por 48 horas de incubação a $37{ }^{\circ} \mathrm{C}$ e $5 \%$ de $\mathrm{CO}_{2}$. Como veículo foi utilizado o dimetilsulfóxido (DMSO) na concentração $0,4 \%$ v/v. Para verificação do efeito citotóxico, foi adicionado a cada poço $10 \mu \mathrm{L}$ do reagente MTT (3-(4,5-dimethylthiazol-2-yl)-2,5-diphenyltetrazolium bromide, Sigma) na concentração $5 \mathrm{mg} \mathrm{mL}^{-1} \mathrm{e}$ incubou-se novamente a $37{ }^{\circ} \mathrm{C}$ por 4 horas. Posteriormente, o sobrenadante foi removido, o formazan foi ressuspendido em $100 \mu \mathrm{L}$ de DMSO e a leitura de absorbância no comprimento de onda de $540 \mathrm{~nm}$ foi realizada em leitora automática de microplacas (Biotek Sinergy HT). Para os cálculos da viabilidade e preparo dos gráficos utilizaram-se os programas Microsoft Excel e Prism5.

Tabela 1. Relação entre o efeito eritematogênico (EE) e a intensidade da radiação (I) em diferentes comprimentos de onda ( $\lambda$ )

\begin{tabular}{cccccccc}
\hline$\lambda(\mathrm{nm})$ & 290 & 295 & 300 & 305 & 310 & 320 & 0,15 \\
\hline $\operatorname{EE}(\lambda) \times \mathrm{I}(\lambda)$ & 0,0150 & 0,0817 & 0,2874 & 0,3278 & 0,0839 \\
\hline
\end{tabular}




\section{Avaliação da atividade antiviral}

\section{Cultura de células e estoque viral}

Vírus Zika (ZIKV), cepa ZIKV/H.sapiens/Brazil/PE243/2015, foram replicados em células $\mathrm{C} 6 / 36$ (ATCC ${ }^{\circledR} \mathrm{CRL}-1660^{\mathrm{TM}}$ ) em meio L-15 (Leibovitz's L-15) suplementado com 2\% de Soro Fetal Bovino (SFB) e posteriormente estocados. Para os ensaios de citotoxicidade e titulação viral foram utilizadas células Vero (ATCC ${ }^{\circledast}$ CCL-81TM), mantidas em meio DMEM (Dulbecco's Modified Eagle' Medium) suplementado com SFB a $37^{\circ} \mathrm{C}$ e atmosfera de $5 \%$ de $\mathrm{CO}_{2}$.

\section{Avaliação da citotoxicidade contra células Vero}

O método de avaliação da viabilidade celular por MTT [brometo de 3-(4,5-dimetiltiazol-2-il)-2,5-difeniltetrazólio) Invitrogen $\left.{ }^{\mathrm{TM}}\right]$ foi utilizado para determinar a citotoxicidade dos compostos frente às células Vero. Placas de 96 poços foram semeadas com $5 \times 10^{3}$ células Vero por poço e incubadas até confluência. As células foram então expostas por 24 horas a diferentes concentrações dos compostos partindo de $1000 \mu \mathrm{mol} \mathrm{L}{ }^{-1}$ até $1 \mu \mathrm{mol} \mathrm{L} \mathrm{L}^{-1}$. Após esse período, o meio com os compostos foi substituído por DMEM contendo MTT em uma diluição final de $0,5 \mathrm{mg} \mathrm{mL}^{-1} \mathrm{e}$ incubado novamente por 4 horas a $37{ }^{\circ} \mathrm{C}$. O sobrenadante então foi substituído por $100 \mu \mathrm{L} /$ poço de dimetilsulfóxido e após breve agitação, a absorbância foi medida em $540 \mathrm{~nm}$ e os resultados expressos por uma regressão não linear, na qual o controle negativo (células sem presença de composto sob avaliação) foi considerado como $100 \%$ de viabilidade.

\section{Triagem antiviral}

A triagem antiviral dos compostos foi feita utilizando como base o valor de $\mathrm{CC}_{50}$ de cada composto obtido do ensaio de citotoxicidade. Após confluência de aproximadamente $80 \%$ das células Vero em placas de 96 poços, o Zika Vírus (ZIKV) foi previamente incubado por 1 hora a $37^{\circ} \mathrm{C}$ com o composto a ser testado, adicionado na monocamada de células e incubado por mais 90 minutos. Decorrido esse período, o conteúdo dos poços foi substituído por DMEM e as placas incubadas por até 7 dias a $37^{\circ} \mathrm{Ce} 5 \% \mathrm{CO}_{2}$. O controle negativo (células não infectadas com o vírus) foi considerado como 100\% de viabilidade e o controle positivo (células infectadas com ZIKV) como $0 \%$. A viabilidade celular foi avaliada pelo método MTT.

Predição de características farmacocinéticas e toxicidade dos derivados triazólicos da benzofenona 4a-4n e 5a-5m

A predição das características farmacocinéticas e de toxicidade sistêmica foi realizada por análises computacionais utilizando três diferentes programas. O programa Marvin Sketch versão 16.6.20.0 (http://www.chemaxon.com/products/marvin/marvinsketch/) foi utilizado para predição do coeficiente de partição (LogP) e o coeficiente foi calculado utilizando o método Consensus e concentrações padrões de íons cloro, potássio e sódio de $0,1 \mathrm{~mol} \mathrm{~L}^{-1}$. A probabilidade de absorção intestinal e atravessar a barreira hematoencefálica de humanos, bem como a toxicidade aguda para ratos foram preditos utilizando o website admetSAR versão 2.0 (http://lmmd.ecust.edu.cn/ admetsar1/home/). A probabilidade de induzir toxicidade cutânea por sensibilização foi predita pelo website Pred-skin versão 2.0 (http:// labmol.com.br/predskin/) e ambos os valores dos parâmetros Human skin sensitization e Murine local lymph node assay (LLNA) Multiclass Pred foram recuperados.

\section{RESULTADOS E DISCUSSÃO}

\section{Síntese dos derivados da benzofenona contendo núcleo 1,2,3-triazólico}

Os compostos triazólicos derivados da benzofenona foram preparados em três etapas como apresentado no Esquema 1.

A primeira etapa envolveu a reação de redução da benzofenona disponível comercialmente com o boroidreto de sódio $\left(\mathrm{NaBH}_{4}\right)$ em etanol, resultando na obtenção do difenilmetanol (1). Uma vez sintetizado, o difenilmetanol foi tratado com brometo de propargila e solução aquosa de $\mathrm{NaOH}$, na presença do catalisador de transferência de fase brometo de tetrabutilamônio $\left.(\mathrm{Bu})_{4} \mathrm{NBr}\right)$, resultando,

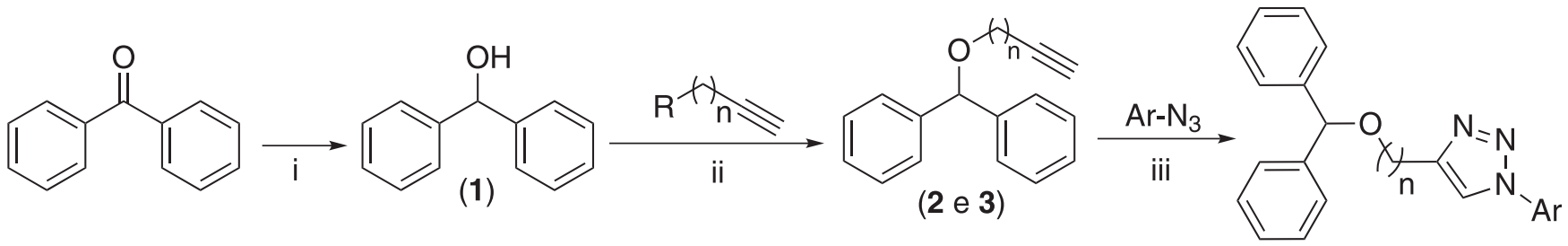

$$
\text { Sendo: } \begin{aligned}
\mathrm{n} & =1, \mathrm{R}=-\mathrm{Br}(\mathbf{4 a}-\mathbf{4 n}) \\
\mathrm{n} & =3, \mathrm{R}=-\mathrm{OSO}_{2} \mathrm{CH}_{3}(\mathbf{5 a}-\mathbf{5 m})
\end{aligned}
$$

(4a-4n e $5 a-5 m)$

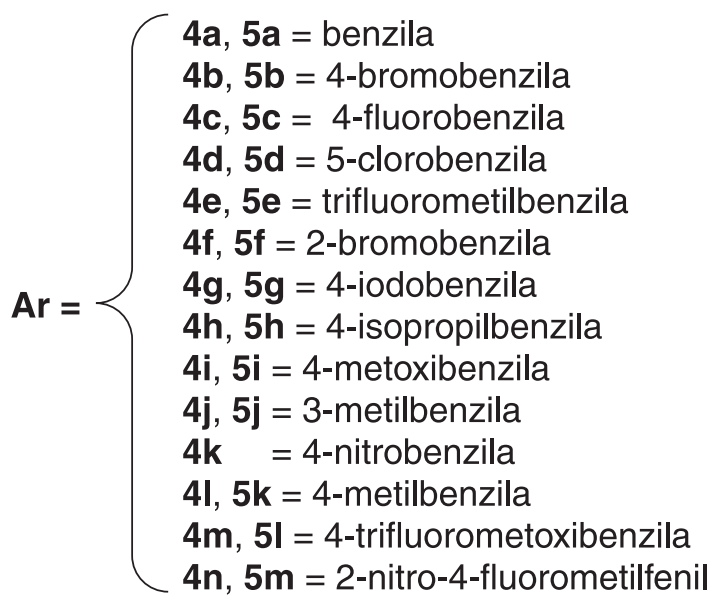

Esquema 1. Preparação dos compostos triazólicos derivados da benzofenona. Reagentes e condições: (i) $\mathrm{NaBH}_{4} / \mathrm{EtOH}$, (ii) $(\mathrm{Bu})_{4} \mathrm{NBr}, 35 \%$ aq. $\mathrm{NaOH}$, tolueno, (iii) Ascorbato de sódio, $\mathrm{CH}_{2} \mathrm{Cl}_{2}, \mathrm{H}_{2} \mathrm{O}, \mathrm{CuSO}_{4} \cdot 5 \mathrm{H}_{2} \mathrm{O}$, t.a. 
via substituição nucleofílica bimolecular, na formação do alquino terminal 2 com $78 \%$ de rendimento. De forma análoga ao composto 2, o alquino 3 foi preparado em $65 \%$ de rendimento, via reação de substituição nucleofílica bimolecular entre o difenilmetanol e o pent-4-in-1-ilmetanosulfonato. Este último por sua vez, foi sintetizado a partir do álcool pent-4-in-1-ol. ${ }^{27} \mathrm{Na}$ última etapa da rota sintética, os derivados da benzofenona contendo núcleos triazólicos $\mathbf{4 a - 4 n}$ foram obtidos empregando-se condições reacionais brandas e com rendimentos variando de $42 \%-88 \%$, via reações "click" catalisadas por cobre(I) entre o alquino 2 e diferentes azidas orgânicas. ${ }^{28}$ As azidas empregadas na síntese dos derivados triazólicos foram preparadas de forma similar ao descrito na literatura. ${ }^{29}$

Com o intuito de avaliar a influência do tamanho da cadeia carbônica nas atividades biológicas dos compostos, outra série de derivados da benzofenona contendo o núcleo 1,2,3-triazólico 5a-5m foi obtida de forma semelhante à síntese dos compostos triazólicos discutidos anteriormente (Esquema 1), com rendimentos variando entre $37 \%-77 \%$.

\section{Descrição dos resultados dos ensaios de avaliação da atividade fotoprotetora}

Os compostos $\mathbf{4 a - 4 n}$ e $\mathbf{5 a - 5 m}$ assim como o controle positivo Benzofenona-3 foram submetidos a testes para a avaliação de suas atividades fotoprotetoras aplicando-se a metodologia descrita por Mansur e colaboradores. ${ }^{23}$ Esse método além de ser considerado simples, preciso e rápido na obtenção de resultados, é muito empregado a fim de facilitar as determinações dos FPS in vitro e eliminar os riscos para a saúde dos seres humanos. ${ }^{23,30} \mathrm{Na}$ Tabela 2, estão descritos os valores de FPS obtidos para os derivados da benzofenona 4a-4n e 5a-5m na faixa do UVB (290-320 nm).

Conforme apresentado na Tabela 2, dentre os derivados da benzofenona sintetizados somente o composto $\mathbf{4 k}$, que apresenta um grupo 4-nitrobenzila ligado à porção triazólica, foi aquele que apresentou o maior efeito fotoprotetor, com FPS-UVB de 6,9 \pm 0,53 na concentração de $3,0 \times 10^{-4} \mathrm{~mol} \mathrm{~L}^{-1}$. Esse valor é inferior ao do padrão Benzofenona-3, utilizado como controle positivo, cujo FPS foi igual a 29,2 $\pm 0,16$. Os demais compostos triazólicos apresentaram um FPS inferior a 3,45 .

De acordo com a resolução - RDC $\mathrm{N}^{\circ} 30$, aprovada em $1^{\circ}$ de junho de 2012,,$^{25}$ um produto para ser considerado adequado para uso e comercializado como protetor solar deve apresentar um fator de proteção igual ou superior a 6 (Tabela 3 ).

Conforme descrito anteriormente, o valor do FPS in vitro calculado para a substância $4 \mathbf{k}$ foi de $6,9 \pm 0,53$. Considerando-se esta informação, pode-se dizer que esta substância atende ao que é preconizado pela ANVISA com respeito aos protetores solares, podendo ser considerado um composto para assegurar a proteção dos indivíduos com foto tipos menos sensíveis às queimaduras solares.

\section{Avaliação da atividade citotóxica}

Os compostos triazólicos derivados da benzofenona sintetizados foram avaliados em relação aos seus efeitos citotóxicos contra as linhagens tumorais MDA-MB-231 (adenocarcinoma de mama) e B16F10 (melanoma metastático murino). Conforme mostrado na Figura 1A, na concentração $100 \mu \mathrm{mol} \mathrm{L} \mathrm{L}^{-1}$, os compostos que apresentaram maior atividade citotóxica contra a linhagem MDA-MB-231

Tabela 2. Resultados da avaliação da atividade fotoprotetora dos compostos triazólicos derivados da benzofenona<smiles>C#CCOC(c1ccccc1)c1ccc(I)cc1</smiles>

\begin{tabular}{|c|c|c|c|c|}
\hline $\mathrm{Ar}$ & Composto & FPS in vitro & Composto & FPS in vitro \\
\hline Benzila & $4 a$ & $0,24 \pm 0,01$ & $5 \mathbf{a}$ & $-0,07 \pm 0,008$ \\
\hline 4-bromobenzila & $4 b$ & $0,72 \pm 0,03$ & $5 \mathbf{b}$ & $-0,09 \pm 0,01$ \\
\hline 4-fluorobenzila & $4 c$ & $0,12 \pm 0,004$ & $5 c$ & $0,05 \pm 0,01$ \\
\hline 4-clorobenzila & $4 d$ & $0,88 \pm 0,04$ & $5 d$ & $0,22 \pm 0,03$ \\
\hline 4-trifluorometilbenzila & $4 e$ & $0,52 \pm 0,05$ & $5 e$ & $0,01 \pm 0,01$ \\
\hline 2-bromobenzila & $4 f$ & $0,13 \pm 0,003$ & $5 f$ & $3,52 \pm 0,35$ \\
\hline 4-iodobenzila & $4 \mathrm{~g}$ & $-0,02 \pm 0,01$ & $5 g$ & $-0,06 \pm 0,01$ \\
\hline 4-isopropilbenzila & $4 h$ & $0,35 \pm 0,02$ & $5 \mathbf{h}$ & $-0,03 \pm 0,02$ \\
\hline 4-metoxibenzila & $4 \mathbf{i}$ & $1,39 \pm 0,10$ & $5 \mathbf{i}$ & $0,03 \pm 0,007$ \\
\hline 3-metilbenzila & $4 j$ & $0,24 \pm 0,003$ & $5 \mathbf{j}$ & $-0,06 \pm 0,01$ \\
\hline 4-nitrobenzila & $4 k$ & $6,9 \pm 0,53$ & - & - \\
\hline 4-metilbenzila & 41 & $0,16 \pm 0,01$ & $5 \mathbf{k}$ & $0,013 \pm 0,01$ \\
\hline 4-trifluorometoxibenzila & $4 m$ & $0,16 \pm 0,003$ & 51 & $-0,07 \pm 0,008$ \\
\hline 2-nitro-4-fluorometilfenila & $4 n$ & $2,34 \pm 0,08$ & $5 \mathrm{~m}$ & $3,45 \pm 0,09$ \\
\hline Benzofenona-3 (controle positivo) & & $29,2 \pm 0,16$ & & \\
\hline
\end{tabular}

(-): Devido à instabilidade do composto triazólico contendo a porção 4-nitro em sua estrutura, à temperatura ambiente, não foi possível obtê-lo. FPS = Fator de proteção solar. 
Tabela 3. Determinação adequada do FPS para cada tipo de pele

\begin{tabular}{lcc}
\hline Fototipos & Grau de proteção & FPS \\
\hline Pouco sensível à queimadura solar & Baixa proteção & $6,0-15$ \\
Moderadamente sensível à queimadura solar & Média proteção & Alta proteção \\
Muito sensível à queimadura solar & Proteção muito alta & $30,0-50,0$ \\
Extremamente sensível à queimadura solar & $>50,0$ e $<100$
\end{tabular}

foram $\mathbf{4 b}, \mathbf{4 d}$ e $\mathbf{5 h}$, os quais reduziram a viabilidade celular em 56,3, 53,7 e $54,4 \%$, respectivamente, podendo ser considerados moderadamente citotóxicos por indicarem $\mathrm{IC}_{50}<100 \mu \mathrm{mol} \mathrm{L} \mathrm{L}^{-1}$. Nessa mesma concentração, os compostos $\mathbf{4 e}, \mathbf{4 g}, \mathbf{5}$ e e $\mathbf{5 l}$ também indicaram efeito citotóxico significativo, uma vez que reduziram a viabilidade celular em pelo menos $30 \%$, resultado similar ao observado para o flavonoide morina, o qual possui atividade antimetastática sobre células MDA-MB-231. ${ }^{31}$ Por sua vez, na concentração $50 \mu \mathrm{mol} \mathrm{L}{ }^{-1}$, os compostos $\mathbf{4 b}, \mathbf{4 d}, \mathbf{4 e}, \mathbf{5 e}, \mathbf{5 h}$ e $\mathbf{5 l}$ também foram capazes de reduzir a viabilidade celular em pelo menos $30 \%$ (Figura 1B), confirmando assim o potencial citotóxico destas substâncias sobre a linhagem de adenocarcinoma de mama.
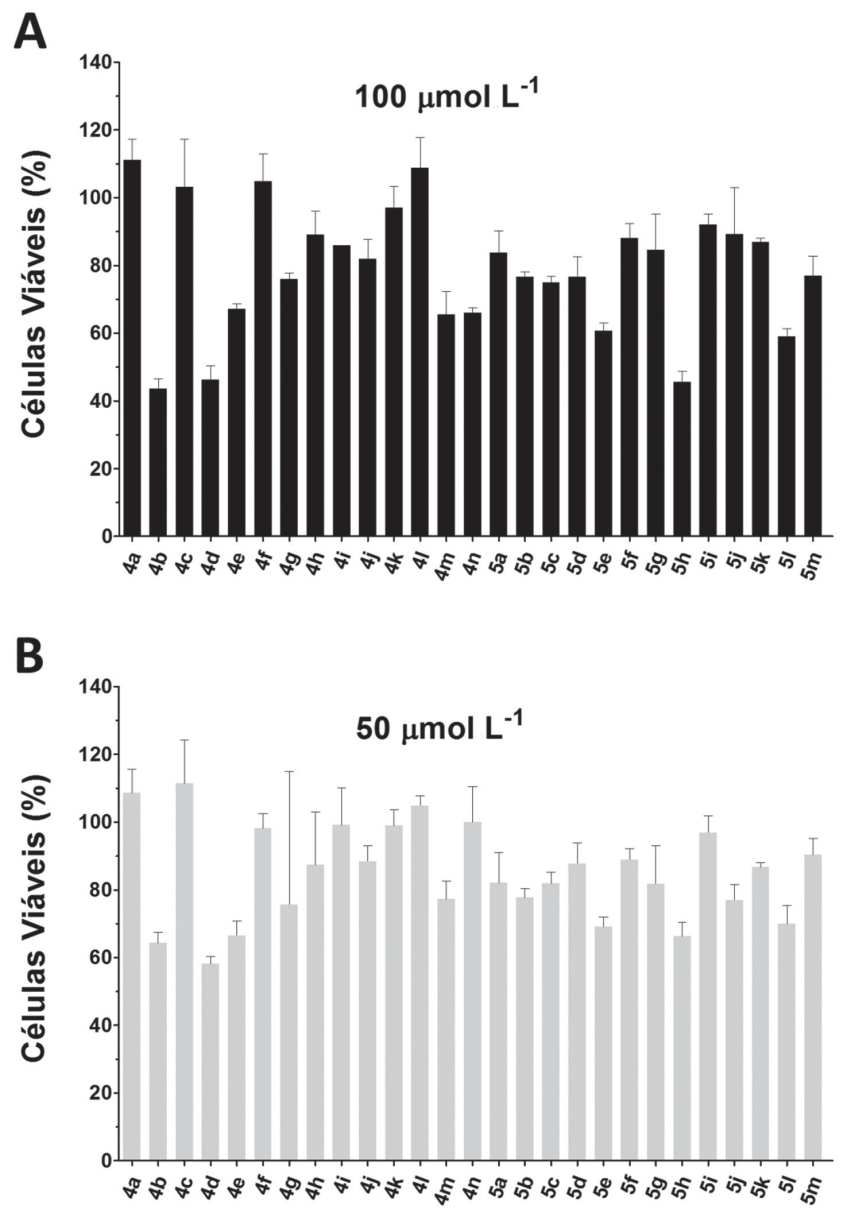

Figura 1. Efeito dos compostos triazólicos derivados da benzofenona sobre a viabilidade (\%) da linhagem celular MDA-MB-231 após 48 horas de exposição aos compostos. É possível inferir a partir dos resultados obtidos que os compostos $\mathbf{4 b}, \mathbf{4}$ e e 5 h apresentam $\mathrm{IC}_{50}<100 \mu \mathrm{mol} \mathrm{L}^{-1}$. Os dados estão apresentados como média \pm desvio padrão

Em relação ao efeito citotóxico sobre a linhagem de melanoma metastático B16F10, a qual é sabidamente mais resistente ao tratamento quimioterápico em geral, ${ }^{32}$ apenas os compostos $\mathbf{5 b}, \mathbf{5 c}, \mathbf{5 j}$ e
$5 \mathbf{l}$ apresentaram atividade citotóxica na concentração $100 \mu \mathrm{mol} \mathrm{L} \mathrm{L}^{-1}$, reduzindo a viabilidade celular em aproximadamente $20 \%$ (dados não mostrados).

\section{Avaliação da atividade antiviral}

Citotoxicidade dos derivados triazólicos frente às células Vero

A avaliação do efeito citotóxico frente às células Vero dos compostos sintetizados revelou que apenas $\mathbf{4 d}$ apresentou citotoxicidade inferior a $100 \mu \mathrm{mol} \mathrm{L}{ }^{-1}$. Os demais compostos, conforme apresentado na Tabela 4, apresentaram baixa toxidade frente às células Vero. Os valores de citotoxicidade são representados por $\mathrm{CC}_{50}$ e correspondem a concentração que resulta na morte de $50 \%$ das células expostas a concentrações crescentes do composto.

\section{Triagem antiviral}

Conforme pode ser observado na Figura 2, os compostos $\mathbf{5 j}$ e $\mathbf{5 h}$ foram os mais eficientes em termos de manutenção da viabilidade

Tabela 4. Citotoxicidade dos derivados triazólicos da benzofenona frente às células Vero

\begin{tabular}{cc}
\hline Composto & $\mathrm{CC}_{50}\left(\mu \mathrm{mol} \mathrm{L}^{-1}\right)$ \\
\hline $\mathbf{4 a}$ & $444,20 \pm 25,59$ \\
$\mathbf{4 b}$ & $122,30 \pm 12,51$ \\
$\mathbf{4 c}$ & $445,70 \pm 29,04$ \\
$\mathbf{4 d}$ & $86,61 \pm 7,84$ \\
$\mathbf{4 e}$ & $165,40 \pm 10,30$ \\
$\mathbf{4 f}$ & $462,50 \pm 27,42$ \\
$\mathbf{4 g}$ & $147,40 \pm 10,75$ \\
$\mathbf{4 h}$ & $445,40 \pm 77,18$ \\
$\mathbf{4 i}$ & $299,60 \pm 5,23$ \\
$\mathbf{4 j}$ & $453,80 \pm 5,49$ \\
$\mathbf{4 k}$ & $449,60 \pm 71,82$ \\
$\mathbf{4 l}$ & $400,80 \pm 17,82$ \\
$\mathbf{4 m}$ & $154,00 \pm 4,24$ \\
$\mathbf{4 n}$ & $395,20 \pm 20,92$ \\
$\mathbf{5 a}$ & $358,95 \pm 75,38$ \\
$\mathbf{5 b}$ & $257,63 \pm 24,32$ \\
$\mathbf{5 c}$ & $386,37 \pm 58,76$ \\
$\mathbf{5 d}$ & $262,33 \pm 6,02$ \\
$\mathbf{5 e}$ & $196,20 \pm 2,55$ \\
$\mathbf{5 f}$ & - \\
$\mathbf{5 g}$ & $409,70 \pm 58,73$ \\
$\mathbf{5 h}$ & $288,50 \pm 22,27$ \\
$\mathbf{5 i}$ & $296,95 \pm 20,18$ \\
$\mathbf{5 j}$ & $260,35 \pm 25,79$ \\
$\mathbf{5 k}$ & $418,37 \pm 17,71$ \\
$\mathbf{5 l}$ & $249,50 \pm 14,00$ \\
$\mathbf{5 m}$ & $413,27 \pm 19,88$ \\
\hline &
\end{tabular}

(-): citotoxicidade não determinada devido à baixa solubilidade da substância 5f. 


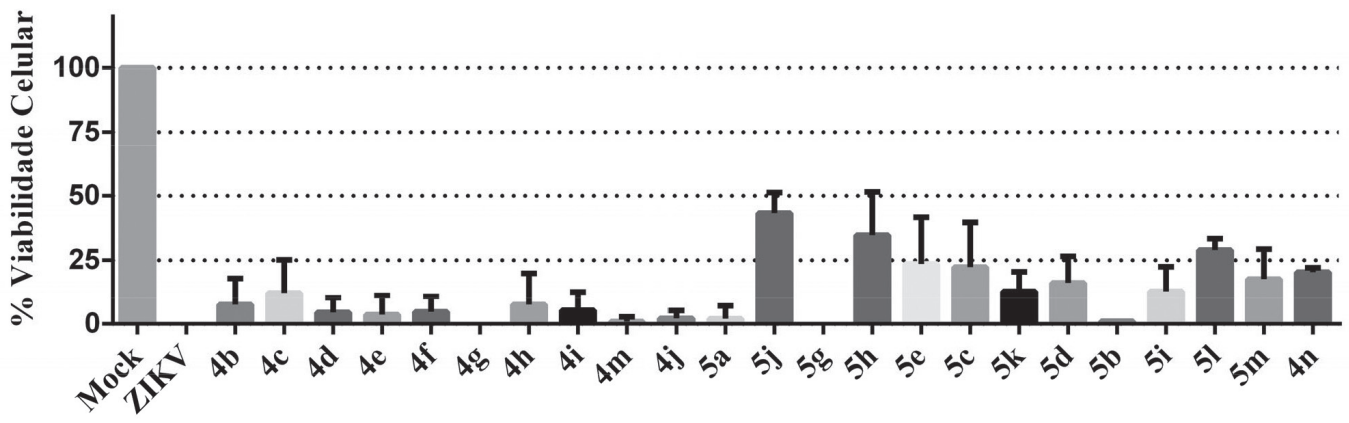

Figura 2. Triagem Antiviral contra ZIKV. Como controle negativo, células foram infectadas com MOI 1 do vírus (ZIKV) e consideradas como 0\% de viabilidade celular. (Mock) células não infectadas, controle positivo. A viabilidade celular foi avaliada pelo método MTT. Os compostos não mostrados no gráfico sofreram precipitação durante os bioensaios e não foram avaliados

celular (aproximadamente $43 \%$ e $32 \%$, respectivamente). É importante destacar que alguns compostos não puderam ser avaliados devido a problemas de precipitação durante a condução dos ensaios de avaliação de atividade antiviral.

Para ser utilizado em ensaios subsequentes em avaliações de compostos como antivirais, é desejável uma manutenção mínima de $50 \%$ da viabilidade celular. Nesse contexto, nenhum dos compostos analisados foi elegível para ser empregado em ensaios subsequentes.

\section{Predição das características farmacocinéticas e de toxicidade dos compostos 4a-4n e 5a-5m}

As características farmacocinéticas e de toxicidade in vivo foram preditas utilizando três diferentes programas e estão resumidas na Tabela 5. O coeficiente de partição (LogP) predito pelo programa Marvin Sketch indica que a maioria dos compostos possuem baixa polaridade e são compatíveis com a alta probabilidade de absorção

Tabela 5. Predição de características farmacocinéticas e de toxicidade dos compostos

\begin{tabular}{|c|c|c|c|c|c|c|}
\hline \multirow[b]{2}{*}{ Composto } & \multirow{2}{*}{$\begin{array}{c}\text { Programa } \\
\text { Marvin Sketch } \\
\text { LogP }\end{array}$} & \multicolumn{3}{|c|}{ Programa admetSAR } & \multicolumn{2}{|c|}{ Programa Pred-Skin } \\
\hline & & $\begin{array}{l}\text { Probabilidade de } \\
\text { atravessar a BHE }\end{array}$ & $\begin{array}{l}\text { Probabilidade de } \\
\text { absorção intestinal } \\
\text { humana }\end{array}$ & $\begin{array}{c}\text { Toxicidade aguda } \\
\text { em ratos } \\
\left(\mathrm{LD}_{50} \mathrm{em} \mathrm{mol} \mathrm{Kg}^{-1}\right)\end{array}$ & $\begin{array}{c}\text { Probabilidade de } \\
\text { induzir sensibilidade } \\
\text { por LLNA }\end{array}$ & $\begin{array}{c}\text { Probabilidade de } \\
\text { induzir sensibilidade } \\
\text { em pele humana }\end{array}$ \\
\hline $4 a$ & 5,14 & $98,50 \%$ & $100,00 \%$ & 2,31 & $50 \%$ (Baixa) & $50 \%$ (Baixa) \\
\hline $4 b$ & 5,91 & $98,11 \%$ & $100,00 \%$ & 2,40 & $50 \%$ (Baixa) & 60\% (Média) \\
\hline $4 c$ & 5,29 & $98,65 \%$ & $100,00 \%$ & 2,42 & $50 \%$ (Baixa) & $50 \%$ (Baixa) \\
\hline $4 d$ & 5,75 & $98,17 \%$ & $100,00 \%$ & 2,36 & 60\% (Média) & $50 \%$ (Baixa) \\
\hline $4 e$ & 6,02 & $98,54 \%$ & $100,00 \%$ & 2,48 & $50 \%$ (Baixa) & $50 \%$ (Baixa) \\
\hline $4 f$ & 5,91 & $97,74 \%$ & $100,00 \%$ & 2,37 & 60\% (Média) & $50 \%$ (Baixa) \\
\hline $4 g$ & 6,07 & $97,89 \%$ & $99,28 \%$ & 2,38 & 60\% (Média) & 60\% (Média) \\
\hline $4 h$ & 6,39 & $95,80 \%$ & $100,00 \%$ & 2,39 & 60\% (Média) & 60\% (Média) \\
\hline $4 \mathbf{i}$ & 4,99 & $97,90 \%$ & $100,00 \%$ & 2,26 & 60\% (Média) & 60\% (Média) \\
\hline $4 \mathbf{j}$ & 5,66 & $97,89 \%$ & $100,00 \%$ & 2,32 & 60\% (Média) & 60\% (Média) \\
\hline $4 k$ & $-0,27$ & $93,20 \%$ & $100,00 \%$ & 2,35 & $50 \%$ (Baixa) & $50 \%$ (Baixa) \\
\hline 41 & 5,66 & $97,89 \%$ & $100,00 \%$ & 2,32 & $50 \%$ (Baixa) & $50 \%$ (Baixa) \\
\hline $4 m$ & 6,58 & $98,55 \%$ & $100,00 \%$ & 2,45 & $50 \%$ (Baixa) & $50 \%$ (Baixa) \\
\hline $4 n$ & $-0,21$ & $91,84 \%$ & $100,00 \%$ & 2,47 & $50 \%$ (Baixa) & $50 \%$ (Baixa) \\
\hline $5 \mathbf{a}$ & 5,67 & $98,93 \%$ & $99,67 \%$ & 2,36 & $50 \%$ (Baixa) & $50 \%$ (Baixa) \\
\hline $5 \mathbf{b}$ & 6,44 & $98,63 \%$ & $99,60 \%$ & 2,46 & $60 \%$ (Média) & 60\% (Média) \\
\hline $5 c$ & 5,81 & $99,03 \%$ & $99,72 \%$ & 2,50 & $50 \%$ (Baixa) & $50 \%$ (Baixa) \\
\hline $5 d$ & 6,27 & $98,73 \%$ & $99,72 \%$ & 2,43 & $50 \%$ (Baixa) & $50 \%$ (Baixa) \\
\hline $5 e$ & 6,55 & $99,10 \%$ & $100,00 \%$ & 2,57 & $50 \%$ (Baixa) & $50 \%$ (Baixa) \\
\hline $5 f$ & 6,44 & $98,33 \%$ & $99,57 \%$ & 2,48 & $50 \%$ (Baixa) & $50 \%$ (Baixa) \\
\hline $5 g$ & 6,60 & $98,47 \%$ & $98,53 \%$ & 2,45 & 60\% (Média) & 60\% (Média) \\
\hline $5 h$ & 6,91 & $96,91 \%$ & $100,00 \%$ & 2,43 & $50 \%$ (Baixa) & $60 \%$ (Média) \\
\hline $5 \mathbf{i}$ & 5,51 & $98,68 \%$ & $100,00 \%$ & 2,29 & $50 \%$ (Baixa) & 60\% (Média) \\
\hline $5 \mathbf{j}$ & 6,18 & $98,55 \%$ & $100,00 \%$ & 2,40 & 60\% (Média) & 60\% (Média) \\
\hline $5 \mathbf{k}$ & 6,18 & $98,60 \%$ & $100,00 \%$ & 2,37 & $50 \%$ (Baixa) & $50 \%$ (Baixa) \\
\hline 51 & 7,10 & $99,15 \%$ & $100,00 \%$ & 2,51 & $50 \%$ (Baixa) & $50 \%$ (Baixa) \\
\hline $5 \mathrm{~m}$ & 0,23 & $94,02 \%$ & $100,00 \%$ & 2,54 & $50 \%$ (Baixa) & $50 \%$ (Baixa) \\
\hline
\end{tabular}

BHE, Barreira hematoencefálica. LLNA, Murine local lymph node assay. 
intestinal e capacidade de atravessar a barreira hematoencefálica. Essas características são importantes para moléculas que serão utilizadas para tratamento sistêmico de câncer e doenças virais como infecção por Zika. A capacidade de induzir sensibilidade na pele variou de baixa a média, com nenhum dos derivados apresentando elevado potencial de toxicidade cutânea. Entre os compostos com menor potencial de induzir toxicidade por sensibilidade na pele está o composto $\mathbf{4 k}$, que apresentou maior poder fotoprotetor. Apesar de possuir bom potencial de absorção, a toxicidade aguda para ratos variou de 2,31 a 2,57 $\mathrm{mol} \mathrm{L}^{-1}$ e deve ser experimentalmente testada antes dos experimentos in vivo.

\section{CONCLUSÃO}

A síntese de vinte e sete derivados triazólicos da benzofenona (compostos 4a-4n e 5a-5m) foi possível empregando-se reações de redução, alquilação e reações "click" (reações CuAAC). Os ensaios de avaliação da atividade fotoprotetora destes compostos demonstraram que a substância $\mathbf{4 k}$ apresentou ação fotoprotetora in vitro, resultando em FPS de aproximadamente 7, enquanto que os demais compostos apresentaram um FPS inferior a 3,5, sendo estes, por tanto, considerados inativos. Diante desses resultados, conclui-se que o derivado da benzofenona $\mathbf{4 k}$ embora apresente um fator de proteção inferior ao controle positivo benzofenona-3, ele ainda se apresenta superior ao desejável e estabelecido como mínimo aceito pela legislação brasileira. Sugere-se que essa substância pode ser empregada em combinação com outros filtros orgânicos, como um possível candidato em formulações fotoprotetoras para aumentar a proteção contra os raios UVB. Além disso, a otimização de sua estrutura poderá resultar futuramente no desenvolvimento de uma substância eficaz para aplicações como filtro solar.

Mesmo não apresentando resultados de manutenção da viabilidade celular igual ou superior a 50\% como desejável, os compostos $\mathbf{5 j}$ e $\mathbf{5 h}$ ainda assim apresentam resultados significativos com respeito ao ensaio contra o ZIKV. Já os compostos $\mathbf{4 b}$, $\mathbf{4 d}$ e $\mathbf{5} \mathbf{h}$ foram capazes de significativamente inibir a viabilidade de linhagem de câncer de mama humano e terão seus mecanismos de ação investigados. Os compostos também apresentam alto potencial de ser absorvidos pelo intestino humano e baixa capacidade de induzir sensibilidade na pele, vias de administração de interesse para tratamento antiviral, anticâncer e fotoprotetora, respectivamente. Porém, a toxicidade oral dos compostos deve ser investigada em futuros experimentos, uma vez que $\mathrm{LD}_{50}$ predita para camundongo ficou abaixo de $3 \mathrm{~mol} \mathrm{~kg}$.

\section{MATERIAL SUPLEMENTAR}

Todos os dados espectroscópicos utilizados neste trabalho estão disponíveis em http://quimicanova.sbq.org.br, na forma de arquivo PDF, com acesso livre.

\section{AGRADECIMENTOS}

À Fundação de Amparo à Pesquisa do Estado de Minas Gerais (FAPEMIG) pelo apoio financeiro (CEX- APQ-02432-14; CEX APQ-03245-15). À Coordenação de Aperfeiçoamento de Pessoal (CAPES) pela concessão de bolsa de estudos à Ângela Maria Almeida Lima.

\section{REFERÊNCIAS}

1. Cuesta-Rubio, O.; Piccinelli, A. L.; Rastrelli, L. In Studies in Natural Products Chemistry, Vol. 32; Rahman, A.-ur., ed.; Elsevier: Amsterdan, 2005, p. 671.
2. Baggett. S.; Mazzola, E. P.; Kennelly, E. J. In Studies in Natural Products Chemistry, Vol. 32; Rahman, A.-ur., ed.; Elsevier: Amsterdan, 2005, p. 721.

3. Lima, A. M. A.; Teixeira, R. R. In Frontiers in Natural Product Chemistry, Vol. 3; Rahman, A.-ur., ed.; Bentham Science Publishers: Sharjah, 2017, p. 293.

4. De Paula, L. R.; Parussulo, A. L. A.; Araki, K.; Toma, H. E.; J. Pharm. Sci. 2012, 101, 726.

5. Nascimento, L. F.; Santos, E. P.; Aguiar, A. P.; Rev. Virtual Quim. 2014, 6, 190.

6. Santos, E. P.; Freitas, Z. M.; Souza, K. R.; Garcia, S.; Int. J. Cosmet. Sci. 1999, 21, 1

7. Araújo, C. R. M.; Santos, V. L. A.; Guimarães, D. G.; Oliveira-Junior, R. G.; Almeida, J. R. G. S.; Gonsalves, A. A.; Rev. Virtual Quim. 2014, 6, 1702 .

8. Lopes, F. M.; Da Cruz, R. O.; Batista, K. A.; Ensaios e Ciência: Ciências Biológicas, Agrárias e da Saúde 2012, 16, 183.

9. Estimativa 2018: incidência de câncer no Brasil/Instituto Nacional de Câncer José Alencar Gomes da Silva, Coordenação de Prevenção e Vigilância. - Rio de Janeiro: INCA, 2017, 128 p.

10. Borghetti, G. S.; Knorst, M. T.; Rev. Bras. Cienc. Farm. 2006, 42, 531.

11. Balogh, T. S.; Pedriali, C. A.; Baby, A. R.; Velasco, M. V. R.; Kaneko, T. M.; An. Bras. Dermatol. 2011, 86, 732.

12. Cabral, L. D. S.; Pereira, S. O.; Partata, A. K.; Rev. Cient. ITPAC 2011, 4.

13. Flor, J.; Davolos, M. R.; Correa, M. A.; Quim. Nova 2007, 30, 153.

14. Figueiredo, S. A.; Dissertação de Mestrado, Universidade de São Paulo, Brasil, 2013.

15. Ribeiro, R. P.; Do Santos, V. M.; De Medeiros, B. C.; Silva, V. A.; Volpato, N. M.; Garcia, S.; Infarma 2004, 16, 85.

16. Dutra, E. A.; Dissertação de Mestrado, Universidade de São Paulo, 2000.

17. https://www.cdc.gov/biomonitoring/Benzophenone-3_FactSheet.html, acesso em Maio 2019.

18. Teixeira, R. R.; Bressan, G. C.; Pereira, W. L.; Ferreira, J. G; de Oliveira, F. M.; Thomaz, D. C.; Molecules 2013, 18, 1881.

19. da Silva Maia, A. F.; Siqueira, R. P.; de Oliveira, F. M.; Ferreira, J. G.; da Silva, S. F.; Caiuby, C. A. D.; de Oliveira, L. L.; de Paula, S. O.; Souza, R. A. C.; Guilardi, S.; Bressan, G. C.; Teixeira, R. R.; Bioorg. Med. Chem. Lett. 2016, 26, 2810.

20. Siqueira, R. P.; de Andrade Barros, M. V.; Barbosa, E. A. A.; Onofre, T. S.; Gonçalves, V. H. S.; Pereira, H. S.; Júnior, A. S.; de Oliveira, L. L.; Almeida, M. R.; Fietto, J. L. R.; Teixeira. R. R.; Bressan, G. C.; Eur. J. Med. Chem. 2017, 134, 97.

21. Oliveira, A. F. C. S.; de Souza, A. P. M.; de Oliveira, A. S.; da Silva, M. L.; de Oliveira, F. M.; Santos, E. G.; da Silva, I. E. P.; Ferreira, R. F.; Villela, F. S.; Martins, F. T.; Leal, D. H. S.; Vaz, B. G.; Teixeira, de Paula, S. O.; Eur. J. Med. Chem. 2018, 149, 98.

22. Dheer, D.; Singh, V.; Shankar, R.; Bioorg. Chem. 2017, 71, 30.

23. Mansur, J. S.; Breder, M. N. R.; Mansur, M. C. D.; Azulay, R. D.; An. Bras. Dermatol. 1986, 61, 167.

24. Sayre, R. M.; Agin, P. P.; Levee, G. J.; Marlowe, E.; Photochem. Photobiol. 1979, 29, 559.

25. http://bvsms.saude.gov.br/bvs, acesso em Maio de 2019.

26. Gonçalves, M. C.; Rossoni Junior, J. V.; Rabelo, A. C. S.; Costa, D. C.; Cazati, T.; Taylor, J. G.; dos Santos, V. M. R.; Rev. Virtual Quim. 2018, 10,600 .

27. Teixeira, R. R.; Gazolla, P. A. R.; Da Silva, A. M.; Borsodi, M. P. G.; Bergmann, B. R.; Ferreira, R. S.; Vaz, B. G.; Vasconcelos, G. A.; Lima, W. P.; Eur. J. Med. Chem. 2018, 146, 274.

28. Mose, J. E.; Moorhouse, A. D.; Chem. Soc. Rev. 2007, 36, 1249.

29. Borgati, T, F.; Alves, R. B.; Teixeira, R. R.; De Freitas, R. P.; Perdigão, T. G.; Da Silva, S. F.; dos Santos, A. A.; Bastidas, J. O.; J. Braz. Chem. Soc. 2013, 24, 953. 
30. Alves, L. M.; Aegerter, M. A.; Hata, K.; An. Bras. Dermatol. 1991, 66, 313.

31. Jin, H.; Lee, W. S.; Eun, S. Y.; Jung, H. J.; Park, H.-S.; Kim, G.; Choi, Y. H.; Ryu, C. H.; Jung, J. M.; Hong, S. C.; Shin, S. C.; Kim, H. J.; Int. J. Oncology 2014, 45, 1629.
32. Anvekar, R. A.; Asciolla, J. J.; Lopez-Rivera, E.; Floros, K. V.; Izadmehr, S.; Elkholi, R.; Belbin, G.; Sikora, A. G.; Chipuk, J. E.; Cell Death Dis. 2012, 3, e420. 